\title{
DERECHOS Y GARANTÍAS DE LA DIGNIDAD DE LA PERSONA EN EL PROCESO DE LA MUERTE: ESPECIAL REFERENCIA A LAS LEYES AUTONÓMICAS DE ANDALUCÍA, ARAGÓN Y NAVARRA ${ }^{1}$
}

\author{
Maria Lourdes Labaca Zabala²
}

\section{Resumen:}

Tres Comunidades Autónomas españolas han promulgado recientemente Leyes que trata de proteger los derechos de los pacientes en la fase final de su vida. Se ha tratado de proteger la dignidad de los pacientes en la fase terminal y de respetar su voluntad manifestada expresamente.

Palabras clave: Autonomía del paciente, Derecho a rechazo de tratamiento, Proceso de la muerte, Dignidad del paciente, Derecho a morir.

\section{INTRODUCCIÓN}

Teniendo en consideración lo que establecen los Estatutos de Autonomía de Andalucía, Aragón y Navarra en relación con los tratamientos del dolor y los cuidados paliativos integrales, así como, la dignidad de la persona en el proceso de la muerte, estas tres Comunidades Autónomas han desarrollado recientemente Leyes autonómicas en relación a los derechos y garantías de la dignidad de la persona en el proceso de la muerte.

Queremos destacar que las cuestiones relativas al proceso de la muerte han adquirido gran trascendencia y un amplio debate en la sociedad española durante los últimos años. Todo ello como consecuencia del envejecimiento de la población y el incremento de personas con enfermedades crónicas que incluso llegan a una situación terminal y con intenso sufrimiento.

El reconocimiento por parte de la legislación española de la autonomía de la voluntad del paciente ha conseguido que los pacientes tengan una posición activa en el proceso de su enfermedad y su muerte.

Por todo ello, se ha considerado fundamental la regulación de los derechos de los pacientes en fase terminal, con el fin de preservar su dignidad y respetar su autonomía, garantizándoles el pleno y efectivo respeto de su voluntad manifestada expresamente.

\footnotetext{
${ }^{1}$ Investigación realizada con el Proyecto de Investigación de la UPV/EHU 1/13 (2013-2014) sobre el tema: "Los derechos de los pacientes en el ámbito sanitario en España y Francia”.

${ }^{2}$ Profesora Agregada de la Facultad de Derecho de la UPV/EHU. E-mail: marialourdes.labaca@ehu.es
} 
Es por ello que nos vamos a desarrollar, en primer lugar, de la normativa internacional, nacional y autonómica que se ha promulgado durante los últimos años. Seguidamente, nos ocuparemos de las tres Leyes autonómicas sobre los derechos y garantías de la dignidad de la persona en el proceso de la muerte. Finalmente, realizaremos unas conclusiones en las que expondremos nuestra posición en relación a los derechos de las personas en el final de su vida.

\section{ÁMBITO NORMATIVO: LEGISLACIÓN INTERNACIONAL, NACIONAL Y AUTONÓMICA EN EL PROCESO DE LA MUERTE}

La posición que se ha mantenido durante los últimos años por parte de la Jurisprudencia de los Tribunales españoles dispone que el derecho a la vida es un derecho esencial e inalienable, sin el que el resto de los derechos no tendrían existencia posible ${ }^{3}$. Se afirma así también que, la vida es más que un derecho, es un estado de la persona inmanente a la misma, por eso el Estado tiene el deber de adoptar las medidas necesarias para protegerla frente a los ataques de terceros incluso contar la voluntad de sus titulares ${ }^{4}$, por ello, numerosas resoluciones judiciales la califican de valor indisponible y la sustraen del ámbito de la libertad y autonomía de su titular ${ }^{5}$

El Tribunal Constitucional es firme a la hora de resolver los conflictos que se han planteado en los supuestos en los que se ha contrapuesto el binomio vida-muerte, ha señalado que el derecho a la vida tiene un contenido de protección positivo que impide configurarlo como un derecho de libertad que incluya el derecho a la muerte. Por ello, no es posible admitir que la Constitución garantice en su articulado el derecho a decidir sobre la propia muerte ${ }^{6}$.

Destacar que, también en el ámbito internacional se ha establecido la supremacía del derecho a la vida. Se han promulgado distintos Textos internacionales y Recomendaciones del Consejo de Europa en el que se ha definido el derecho a la vida como derecho prioritario, destacando que, a pesar de que un enfermo terminal e incurable haya manifestado su voluntad de morir, esta declaración no puede en sí misma servir de justificación legal para ejecutar acciones dirigidas directamente a causarle la muerte?

\footnotetext{
${ }^{3}$ STC 53/1985, de 11 de abril, F. J. 20 y STC 154/2002, de 18 de julio, F. J. 12.

${ }^{4}$ SSTC 120/1990, de 27 de junio, F. J. 60.

${ }^{5}$ Auto del TS de 22 de diciembre de 1983, SSTS de 27 de marzo de 1990, F. J. 20, Sentencia de la AP de Bilbao de 28 de febrero de 1990, Auto de la AP de Madrid de 15 de febrero de 1990, Auto de la AP de Zaragoza de 16 de febrero de 1990...

${ }^{5}$ Auto del TS de 22 de diciembre de 1983, SSTS de 27 de marzo de 1990, F. J. 2o, Sentencia de la AP de Bilbao de 28 de febrero de 1990, Auto de la AP de Madrid de 15 de febrero de 1990, Auto de la AP de Zaragoza de 16 de febrero de 1990.

${ }^{6}$ STC 120/1990, de 27 de junio, F. J. 6 y y STC 154/2002, de 18 de julio, F. J. 12.

${ }^{7}$ MORENO ANTÓN, M. "Elección de la propia muerte y Derecho: Hacía el reconocimiento jurídico del derecho a morir", en Derecho Sanitario, volumen 12, número 1, enero-junio 2004, pp. 68 y ss. 
En el mismo sentido se ha pronunciado el Tribunal Europeo de Derechos Humanos en su Sentencia de 29 de abril de 2002, Caso Pretty c. Reino Unido. Se ha señalado por parte de este Tribunal que:

"Según se establece en el art. 2 del Convenio de Roma, los Estados están obligados a proteger la vida y que se prohíbe recurrir a la fuerza o a cualquier otro comportamiento susceptible de provocar la muerte de una persona, y en ningún caso confiere al sujeto un derecho a morir que permita recabar la ayuda de terceros o de las autoridades públicas para facilitar la muerte de la persona que está en fase terminal de su enfermedad, aunque la misma haya mostrado su voluntad de morir".

\section{LEGISLACIÓN INTERNACIONAL}

En el ámbito internacional se han promulgado distintas normas y Recomendaciones que directa o indirectamente afectan al ámbito de la dignidad de la persona en la fase terminal de su vida.

La Carta de los Derechos Fundamentales de la Unión Europea $\left(2000 /\right.$ C 364/01) ${ }^{8}$, así como la Carta de los Derechos Fundamentales de la Unión Europea (2007/C 303/01)9 y la Carta de los Derechos Fundamentales de la Unión Europea (2010/C 83/02 ${ }^{10}$ reconoce en su Título I, bajo la rúbrica Dignidad, artículo 1, La Dignidad Humana, afirmando que: “La dignidad humana es inviolable. Será respetada y protegida”, en su artículo $2^{\circ}$ dispone que: "Toda persona tiene derecho a la vida", y en su artículo $3^{\circ}$, hace referencia a la integridad física y psíquica de toda persona, destacando que en el marco de la medicina ... se respetarán en particular los siguientes derechos: a) El consentimiento libre e informado de la persona de que se trate, de acuerdo con las modalidades establecidas en la Ley.

La Conferencia General de la UNESCO aprobó el día 25 de octubre de 2005 la Declaración Universal sobre Bioética y Derechos Humanos ${ }^{11}$, en la que se dispone que se constituye en un objetivo de la Declaración, entre otros,

Promover el respeto de la dignidad humana y proteger los derechos humanos, velando por el respeto de la vida de los seres humanos y las libertades fundamentales, de conformidad con el Derecho International relativo a los derechos humanos ${ }^{12}$

, y que se constituye como principio fundamental, bajo la rúbrica: la Dignidad humana y derechos fundamentales, que

debe respetarse plenamente la dignidad humana, los derechos humanos y las libertades fundamentales, teniendo prioridad respecto al interés exclusivo de la ciencia o la sociedad, el interés y el bienestar de la personal ${ }^{13}$.

\footnotetext{
${ }^{8}$ Diario Oficial de las Comunidades Europeas (364/1, de 18.12.2000. Vigente hasta el día 1 de enero de 2009.

${ }^{9}$ Diario Oficial de la Unión Europea C 303/3, de 14.12.2007,

${ }^{10}$ Diario Oficial de la Unión Europea C 83/391, de 30.03.2010.

${ }^{11}$ Aprobada por la 33a sesión de la Conferencia General de la UNESCO el día 19 de octubre de 2005.

${ }^{12}$ Art. 2-c): Objetivos.

${ }^{13}$ Art. 3-1) y 2). Principios.
} 
Se protegerá la autonomía de la persona en lo que se refiere a la facultad de adoptar decisiones, asumiendo la responsabilidad de éstas y respetando la autonomía de los demás, debiéndose adoptar las medidas necesarias para aquellas personas que no tienen capacidad suficiente para adoptar las decisiones pertinentes ${ }^{14}$. En relación con el consentimiento se afirma que:

"Toda intervención médica preventiva, diagnóstica y terapéutica sólo habrá de llevarse a cabo previo consentimiento libre e informado de la persona interesada, basado en la información adecuada. Cuando proceda, el consentimiento debería ser expreso y la persona interesada podrá revocarlo en todo momento y por cualquier motivo, sin que esto entrañe para ella desventaja o perjuicio alguno"15

y se señalan los requisitos que deben cumplirse a la hora de emitirse el consentimiento por parte de las personas que carecen de capacidad para ello ${ }^{16}$.

Dentro de las funciones que corresponden a los Estados, se establece en el art. 22 de la Declaración de 2005 que: corresponde a los Estados la función de adoptar todas las disposiciones adecuadas, tanto de carácter legislativo como administrativo o de otra índole, para poner en práctica los principios enunciados en la presente Declaración, conforme al Derecho Internacional relativo a los Derechos Humanos, debiendo ser secundadas éstas medidas por otras en los terrenos de la educación, la formación y la información pública, debiendo alentar los Estados la creación de Comités de ética independientes ${ }^{17}$.

También se han promulgado dos Recomendaciones sobre Protección de los Derechos Humanos y la Dignidad de los enfermos terminales y moribundos adoptadas, una por parte de la Asamblea Parlamentaria del Consejo de Europa el día 25 de junio de 1999, (Sesión 24a), la Recomendación 1418 (1999) 18 y la otra, la Recomendación 24/2003, del Comité de Ministros de los Estados Miembros sobre la Organización de cuidados paliativos y memorándum explicativo, del Consejo de Europa ${ }^{19}$ en el que se recomienda a los Estados la adopción

\footnotetext{
${ }^{14}$ Art. 5: Autonomía y responsabilidad individual.

${ }^{15}$ Art. 6.1: Consentimiento.

${ }^{16}$ Art. 7. a) y b): Personas carentes de capacidad para emitir el consentimiento: a) La autorización para proceder a investigaciones y prácticas médicas debería obtenerse conforme a los intereses de la persona interesada y de conformidad con la legislación nacional. Sin embargo, la persona interesada debería estar asociada en la mayor medida posible al proceso de adopción de la decisión de consentimiento, así como al de su revocación;

b) Se deberían llevar a cabo únicamente actividades de investigación que redunden directamente en provecho de la salud de la persona interesada, una vez obtenida la autorización y reunidas las condiciones de protección prescritas por la ley, y si no existe una alternativa de investigación de eficacia comparable con participantes en la investigación capaces de dar su consentimiento. Las actividades de investigación que no entrañen un posible beneficio directo para la salud se deberían llevar a cabo únicamente de modo excepcional, con las mayores restricciones, exponiendo a la persona únicamente a un riesgo y una coerción mínimos y, si se espera que la investigación redunde en provecho de la salud de otras personas de la misma categoría, a reserva de las condiciones prescritas por la ley y de forma compatible con la protección de los derechos humanos de la persona. Se debería respetar la negativa de esas personas a tomar parte en actividades de investigación.

${ }^{17}$ Art. 22.2.

${ }^{18}$ Ver: http://www.unav.es/cdb/acoerec99-1418.html. Consultado (12-08-2013).

${ }^{19}$ Adoptada por el Comité de Ministros el día 12 de noviembre en la 860ª Reunión de Representantes Ministeriales del Consejo de Europa, en el que se contiene un Memorándum sobre cuidados paliativos en los países europeos, definiciones y principios fundamentales, estructuras y servicios, políticas y organización, mejora de la calidad e investigación, educación y formación de profesionales y del voluntariados, comunicación, equipos, trabajo en equipo y planificación de cuidados, voluntariado y duelo.
} vol.07, no. 02, Rio de Janeiro, 2014. pp.710-758 713 
de determinadas medidas en el ámbito legislativo y cualquier otra que sea necesaria para desarrollar en cada uno de los Estados una política nacional coherente e integral para los cuidados paliativos.

La Recomendación 1418 señala que:

1. El Consejo de Europa trata de proteger la dignidad de todos los seres humanos y los derechos que nacen de ella;

2. El progreso médico que hace posible hoy curar enfermedades hasta ahora intratable, los avances de la técnica y el desarrollo de sistemas de resucitación, que hacen posible prolongar la vida de la persona retrasando el momento de la muerte ... todo ello supone que, con frecuencia se ignore la calidad de vida de los enfermos terminales, la soledad a la que se ven sometidos, su sufrimiento, el de sus familiares y el del personal sanitario que los trata, ...;

3. La Resolución 613 de la Asamblea declaró el año 1976 que estaba "convencida de que lo que los enfermos terminales quieren es, principalmente, morir en paz y dignidad, con el apoyo y la compañía, si es posible de su familia y amigos", la Recomendación 779 añadió que "prolongar la vida no debe ser, en sí mismo, el fin exclusivo de la práctica médica, que debe ocuparse igualmente por el alivio del sufrimiento";

4. La Convención Europea para la Protección de los Derechos Humanos y la Dignidad del ser humano en relación con la aplicación de la Biología y la Medicina ha sentado principios importantes y afirmado el camino, aun cuando no se refiera explícitamente a las necesidades especificas de los enfermos terminales o moribundo;

5. La obligación de respetar y proteger la dignidad de estas personas deriva de la inviolabilidad de la dignidad humana en todas las etapas de la vida. El respeto y protección encuentra su expresión en proporcionar un medio adecuado que permita al ser humano morir con dignidad;

6. Esta tarea debe llevarse a cabo especialmente en beneficio de los miembros más vulnerables de la sociedad, tal y como demuestran muchas experiencias de sufrimiento del presente y del pasado más próximo. De la misma forma que el ser humano comienza su vida en la debilidad y la dependencia, necesita protección y apoyo al morir.

Los derechos fundamentales que derivan de la dignidad del paciente terminal o moribundo se ven amenazados por diversos factores:

I. Las dificultades de acceso a los cuidados paliativos y un buen manejo del dolor;

II. La frecuente falta de tratamiento del sufrimiento físico y de las necesidades psicológicas, sociales y espirituales; 
III. La prolongación artificial del proceso de muerte, ya por el uso desproporcionado de medios técnicos, ya por la continuación del tratamiento sin consentimiento del paciente;

IV. La falta de formación continuada y apoyo psicológico a los profesionales sanitarios que trabajan en medicina paliativa;

V. La insuficiencia de apoyo y asistencia a los familiares y amigos de los pacientes, que también puede aumentar el sufrimiento humano en sus distintas dimensiones;

VI. $\quad$ El temor de los pacientes a perder el control sobre sí mismos y convertirse en una carga, en seres dependientes por completo de sus familiares o de instituciones;

VII. La carencia o inadecuación de un entorno social e institucional en el que uno pueda separarse para siempre de sus familiares y amigos en paz;

VIII. La insuficiente asignación de financiación y recursos para la asistencia y apoyo de los enfermos terminales o moribundos;

IX. La discriminación social del fenómeno de la debilidad, el morir y la muerte.

Con el fin de proteger los Derechos fundamentales ${ }^{20}$, "La Asamblea insta a los Estados miembros a que su Derecho interno incorpore la protección legal y social necesaria contra estas amenazas y temores que el enfermo terminal o moribundo afronta, y en particular sobre:

I. El morir sometido a síntomas insoportables (por ejemplo, dolor, ahogo, etc.);

II. La prolongación del proceso de la muerte contra la voluntad del enfermo terminal;

III. El morir en el aislamiento social y la degeneración;

IV. El morir bajo el temor de ser una carga social;

V. Las restricciones a los medios de soporte vital por razones económicas;

VI. La falta de fondos y recursos materiales para la asistencia adecuada del enfermo terminal o moribundo.

Así también la Asamblea recomienda, que el Comité de Ministros inste a los Estados miembros del Consejo de Europa a respetar y proteger la dignidad de los enfermos terminales o moribundos en todos los aspectos:

Afirmando y protegiendo el derecho de los enfermos terminales o moribundos a los cuidados paliativos integrales, de modo que se adopten las medidas necesarias para:

I. Asegurar que los cuidados paliativos son un derecho legal e individual en todos los Estados miembros;

II. Proporcionar un acceso equitativo a los cuidados paliativos a todas las personas moribundas o en fase terminal;

\footnotetext{
${ }^{20}$ BASTIDA FREIJEDO, F. J. (2011) “El derecho fundamental a la vida y la autonomía del paciente”, en PRESNO LINERA, M. A. (Coordinador), Autonomía Personal, Cuidados Paliativos y Derecho a la Vida, Procura, no 1-2011.
} 
III. Garantizar que los familiares y amigos son animados a acompañar al enfermo terminal o moribundo y reciben un apoyo profesional en tal empeño. Si la familia y/o las asociaciones de cualquier tipo resultan ser insuficientes o limitadas, se deben facilitar métodos alternativos o complementarios de asistencia médica;

IV. Contar con organizaciones y equipos de asistencia ambulatoria, que aseguren la asistencia paliativa a domicilio en los casos en que esté indicada;

V. Asegurar la cooperación entre todas las personas y profesionales implicados en la asistencia del moribundo o la persona en fase terminal;

VI. Garantizar el desarrollo y mejora de los estándares de calidad en los cuidados del enfermo terminal o moribundo;

VII. Asegurar que la persona en fase terminal o moribunda recibirá un adecuado tratamiento del dolor (a menos que el interesado se niegue) y cuidados paliativos, incluso si tal tratamiento tiene como efecto secundario el acortamiento de la vida;

VIII. Garantizar que los profesionales sanitarios reciben formación para proporcionar una asistencia médica, de enfermería y psicológica a cualquier enfermo terminal o moribundo, en el seno de un equipo coordinado y según los estándares más altos posibles;

IX. Crear e impulsar centros de investigación, enseñanza y capacitación en los campos de la medicina y los cuidados paliativos, así como en tanatología interdisciplinar;

X. Garantizar que al menos los grandes hospitales cuentan con unidades especializadas en cuidados paliativos y hospicios, en los que la medicina paliativa pueda desarrollarse como parte integral del tratamiento médico;

XI. Asegurar que la medicina y los cuidados paliativos se asientan en la conciencia pública como un objetivo importante de la medicina.

Protegiendo el derecho de las personas en fase terminal o moribundas a la autodeterminación, al tiempo que se adoptan las medidas necesarias para:

I. Dar eficacia al derecho de la persona en fase terminal o moribunda a una información veraz y completa, pero proporcionada con compasión, sobre su estado de salud, respetando, en su caso, el deseo del paciente a no ser informado;

II. Hacer posible que el enfermo terminal o la persona moribunda pueda consultar a otro médico distinto del que le atiende habitualmente; 
III. Garantizar que ningún enfermo terminal o persona moribunda sea tratada contra su voluntad y que en esta materia no actúa bajo la influencia o presión de un tercero. Además, se debe garantizar que su voluntad no se configura bajo presiones económicas;

IV. Asegurar que se respetará el rechazo a un tratamiento específico recogido en las directivas avanzadas o testamento vital de un enfermo terminal o persona moribunda serán respetadas. Por otra parte, se deben definir criterios de validez sobre la coherencia de tales directivas avanzadas, así como sobre la delegación en personas próximas y el alcance de su autoridad para decidir en lugar del enfermo. También se debe garantizar que las decisiones de las personas próximas que se subrogan en la voluntad del paciente -que habrán de estar basadas en los deseos expresados con anterioridad por el paciente o en presunciones sobre su voluntad-, se adoptan sólo si el paciente implicado en esa situación no ha formulado deseos expresamente o si no hay una voluntad reconocible. En este contexto, siempre debe haber una conexión clara con los deseos expresados por la persona en cuestión en un periodo de tiempo cercano al momento en que se adopte la decisión -deseos referidos específicamente al morir-, y en condiciones adecuadas, es decir, en ausencia de presiones o incapacidad mental. Se debe asimismo garantizar que no serán admisibles las decisiones subrogadas que se basen en los juicios de valor generales imperantes en la sociedad, y que, en caso de duda, la decisión se inclinará siempre por la vida y su prolongación;

V. Garantizar que -no obstante la responsabilidad última del médico en materia terapéutica- se tienen en cuenta los deseos expresados por un enfermo terminal o persona moribunda en relación con formas particulares de tratamiento, siempre que no atenten contra la dignidad humana;

VI. Asegurarse de que, en situaciones en las que no existen directivas anticipadas o testamento vital, no se infringe el derecho del paciente a la vida.

Es necesario definir un catálogo de tratamientos que en ningún caso pueden ser omitidos o retirados;

Respaldando la prohibición de poner fin a la vida intencionadamente de los enfermos terminales o las personas moribundas, al tiempo que se adoptan las medidas necesarias para:

1. Reconocer que el derecho a la vida, especialmente en relación con los enfermos terminales o las personas moribundas, es garantizado por los Estados miembros, de acuerdo con el artículo 2 de la Convención Europea de Derechos Humanos, según la cual "nadie será privado de su vida intencionadamente...";

2. Reconocer que el deseo de morir no genera el derecho a morir a manos de un tercero;

3. Reconocer que el deseo de morir de un enfermo terminal o una persona moribunda no puede, por sí mismo, constituir una justificación legal para acciones dirigidas a poner fin a su vida. 
Destacar que en la Recomendación 24/2003 se dispone que:

"Los cuidados paliativos son los cuidados activos, integrales, de los pacientes con enfermedades avanzadas y progresivas, que pretenden el control del dolor y otros síntomas, y ofrecen soporte psicológico, social y espiritual, sabiendo que las metas de los cuidados paliativos es la consecución de la mayor calidad de vida posible para los pacientes y sus familiares, que pretender ayudar a los hombres, mujeres y niños con enfermedades avanzadas y progresivas a alcanzar la mayor calidad de vida posible hasta el final, sin pretender acelerar ni posponer la muerte, que son parte integral del sistema de cuidados de salud y un elemento inalienable del derecho de los ciudadanos a los cuidados de salud, y que por tanto es una responsabilidad del Gobierno garantizar que los cuidados paliativos sean accesibles a todos los que lo necesiten, que deben ser de calidad y aplicados humanamente para llevar a cabo una parte esencial de los cuidados de salud de los pacientes próximos al final de sus vidas, que la persona en el final de su vida debe ser tratada por profesionales sanitarios y tienen que disponer de una atención dirigida al mantenimiento de la dignidad y al fomento de la independencia, aliviando los síntomas y maximizando el confort, que los cuidados paliativos, como atención médica, deben orientarse al paciente y estar guiados por las necesidades de los paciente, teniendo siempre en cuenta sus valores y preferencia y que la dignidad y autonomía son preocupaciones esenciales para los pacientes que necesitan cuidados paliativos, realizan una serie de recomendaciones dirigidas a los Estados miembros: 1. Adoptar políticas, legislaciones y otras medidas necesarias para el desarrollo de un marco político nacional coherente e integral para los cuidados paliativos;

2. Dedicar a este fin, siempre que sea posible, las medidas presentadas en el apéndice de esta Recomendación, teniendo en cuenta sus circunstancias nacionales respectivas;

3. Promover el trabajo de grupo internacional entre organizaciones, institutos de investigación y otras agencias activas en el campo de los cuidados paliativos;

4. Dar soporte a una activa y orientada difusión de esta recomendación y de su memorándum explicativo, acompañada por su traducción donde sea pertinente".

El Convenio para la protección de los Derechos Humanos y la Dignidad del Ser Humano con respecto a

las aplicaciones de la Biología y la Medicina ${ }^{21}$ dispone que se adoptarán a través del presente Convenio las medidas adecuadas, en el ámbito de las aplicaciones de la biología y la medicina, para garantizar la dignidad del ser humano y los derechos y libertades fundamentales de la persona ${ }^{22}$ y que tiene por objeto "Proteger al ser humano en su dignidad y su identidad y garantizar a toda persona, sin discriminación alguna, el respeto a su integridad y a sus demás derechos y libertades fundamentales respecto a las aplicaciones de la biología y la medicina, debiendo adoptar los Estados en su legislación interna las medidas necesarias para dar aplicación a lo dispuesto en el presente Convenio" ${ }^{23}$.

\footnotetext{
${ }^{21}$ Instrumento de Ratificación del Convenio para la protección de los derechos humanos y la dignidad del ser humano con respecto a las aplicaciones de la Biología y la Medicina (Convenio relativo a los derechos humanos y la biomedicina), hecho en Oviedo el 4 de abril de 1997 y publicado en el BOE no 251, de 20 de octubre de 1999, vigente desde el día 1 de enero de 2000. España firmó el Convenio el día 4 de abril de 1997 y entró en v Igor el día 1 de enero de 2000.

${ }^{22}$ Preámbulo del Convenio de Oviedo de 1997.

${ }^{23}$ Art. 1 del Convenio de Oviedo 1997: Objetivo y finalidad.
} 


\section{LEGISLACIÓN NACIONAL}

La primera Ley estatal en la que se contiene la mención expresa a la dignidad humana como derecho del paciente en el ámbito sanitario se contiene en la Ley 14/1986, de 25 de abril, General de Sanidad. En su art. 10 se dispone que:

Todos tienen los siguientes derechos respecto a las distintas administraciones públicas sanitarias: Al respeto a su personalidad, dignidad humana e intimidad, sin que pueda ser discriminado por su origen..${ }^{24}$, a la información sobre los servicios sanitarios ${ }^{25}$, a la confidencialidad de toda la información relacionada con su proceso y con su estancia en instituciones sanitarias públicas y privadas que colaboren en el sistema público ${ }^{26}$, y a la información sanitaria ${ }^{27}$ y el consentimiento por escrito ${ }^{28}$.

Por su parte, la Ley 41/2002, de 14 de noviembre, Básica reguladora de la Autonomía del paciente y de los derechos y obligaciones en materia de información y documentación clínica ${ }^{29}$ dispone, dentro de los Principios Generales, el principio básico de la dignidad de la persona humana, el respeto a la autonomía de su voluntad y a su intimidad, debiendo orientarse toda la actividad sanitaria a obtener, utilizar, archivar, custodiar y transmitir la información y la documentación clínica ${ }^{30}$. Una cuestión fundamental que se contiene en la presente Ley como principio básico hace referencia al consentimiento del paciente en el ámbito sanitario, consentimiento que deberá obtenerse de forma previa a la realización de cualquier actuación sanitaria y que deberá recabarse una vez de que éste haya obtenido la información adecuada entre las opciones clínicas disponibles, reconociéndose también, el derecho a negarse al tratamiento, encomendándose a los profesionales sanitarios la obligación de prestar asistencia técnica adecuada y de cumplir con los deberes de informar y de respetar las decisiones libre y voluntariamente adoptadas por el paciente ${ }^{31}$.

\section{LEGISLACIÓN AUTONÓMICA} ${ }^{24}$ Art. 10.1 de la Ley de 1986.
${ }^{25}$ Art. 10.2 de la Ley de 1986.
${ }^{26}$ Art. 10.3 de la Ley de 1986.
${ }^{27}$ Art. 10.5 de la Ley de 1986 , derogada a través de la Ley $41 / 2002$, de 14 de noviembre, Básica reguladora de la autonomía del
paciente y de los derechos y obligaciones en materia d información y documentación clínica.
${ }_{28}$ Art. 10.6 de la Ley de 1986 , derogada a través de la Ley $41 / 2002$, de 14 de noviembre, Básica reguladora de la autonomía del
paciente y de los derechos y obligaciones en materia d información y documentación clínica. Para más información, ver: LABACA
ZABALA Ma LOURDES, "El Consentimiento informado en el ámbito sanitario, a propósito de la Ley 41/2002, Básica Reguladora
de la Autonomía del paciente y de los Derechos y Obligaciones en materia de información y documentación clínica", en Saberes:
Revista de Estudios Jurídicos, Económicos y Sociales, volumen no 4, 2006., pp. 3 y ss.

${ }^{29}$ Art. 2 de la Ley 41/2002: Principios Básicos.

${ }^{30}$ LABACA ZABALA Ma LOURDES, "El Consentimiento informado en el ámbito sanitario, a propósito de la Ley 41/2002, Básica Reguladora de la Autonomía del paciente y de los Derechos y Obligaciones en materia de información y documentación clínica”, en Saberes: Revista de Estudios Jurídicos, Económicos y Sociales, volumen no 4, 2006., pp. 5 y ss. LABACA ZABALA Ma LOURDES, "La Ley de voluntades anticipadas en el ámbito de la sanidad del País Vasco", en Revista Âmbito Juridico, Universidad Río Grande-Brasil. Ver: http://www.ambito-juridico.com.br/site/index.php?n_link=revista_artigos_leitura\&artigo_id=1229. (consultado el día 23-04-2013).

${ }^{31}$ Art. 2 de la Ley 41/2002: Principios Básicos. 


\section{Consideraciones previas}

La Ley 41/2002, tiene la característica de ser una Ley Básica, de conformidad con lo establecido en el art. 149.1.1 y y $16^{a}$ de la Constitución, por lo que el Estado y las Comunidades Autónomas adoptarán, en el ámbito de sus respectivas competencias, las medidas necesarias para la efectividad de esta Ley, siendo así también, la presente Ley de aplicación supletoria en determinados ámbitos ${ }^{32}$.

Las competencias en materia de sanidad están prácticamente transferidas a las distintas Comunidades Autónomas y, de hecho, ya existen distintas Leyes de Comunidades Autónomas sobre la materia, como son, por ejemplo: la Ley Catalana, 21/2000, de 29 de diciembre, sobre los Derechos de Información concernientes a la Salud y a la Autonomía del Paciente y a la Documentación Clínica, la Ley Gallega 3/2001, de 28 de mayo, Reguladora del Consentimiento Informado y de la Historia de los pacientes, la Ley Foral de Navarra, 11/2002, de 6 de mayo, sobre los Derechos del Paciente a las Voluntades Anticipadas, a la Información y a la Documentación Clínica, o la Ley Valenciana 1/2003, de 28 de enero, de Derechos e Información al Paciente de la Comunidad Autónoma Valenciana, la Ley 2/1998, de 15 de junio de Salud de Andalucía y la Ley 6/2002, de 15 de abril de Salud de Aragón ${ }^{33}$.

Por el momento, sólo tres Comunidades Autónomas han promulgado Leyes que garantizan la dignidad de la persona en el proceso de la muerte de las que nos ocuparemos seguidamente.

Recientemente, tres Comunidades Autónomas, concretamente Andalucía (2010), Aragón (2011) y Navarra (2011) han promulgado sendas Leyes autonómicas en relación a los derechos y garantías de los pacientes en el proceso de su muerte. Consideramos que estamos en presencia de una normativa que va a garantizar los derechos de los pacientes, el personal sanitario y los centros sanitarios, teniendo en consideración la evolución que ha sufrido la sociedad española en el ámbito de los derechos y garantías de los pacientes al final de su vida. Todo ello favorecerá la seguridad jurídica de las intervenciones sanitarias realizadas por el personal sanitario ${ }^{34}$.

\footnotetext{
${ }^{32}$ Disposición Adicional Primera y Segunda de la Ley 41/2002: Carácter de legislación básica y Aplicación supletoria.

${ }^{33}$ Algunas de estas Leyes sanitarias han sido modificadas posteriormente. Nosotros centraremos el estudio en las Leyes autonómicas de Andalucía, Aragón y Navarra. Ley 2/1998, de 15 de junio, de Salud de Andalucía, última revisión de 27 de mayo de 2010, Ley 16/2011, de 23 de diciembre, de Salud Pública de Andalucía, Ley 6/2002, de 15 de abril, de Salud de Aragón, última modificación de 7 de julio de 2011, y la Ley Foral 10/1990, de 23 de noviembre, de Salud de Navarra, modificado por la Ley Foral 2/2000, de 25 de mayo, última revisión de 13 de abril de 2012, y la Ley Foral 17/2010, de 8 de noviembre, de Derechos y Deberes de las personas en materia de Salud en la Comunidad Foral de Navarra.

${ }^{34}$ Para más información sobre La muerte digna en los Estatutos de Autonomía, ver: RODRIGUEZ, A. "Muerte digna y Derechos en los Estatutos de Autonomía", en Autonomía personal, Cuidados paliativos y Derecho a la vida, PRESNO LINERA M. A. (Coordinador), Procura, no 1, 2011, pp. 2 a 17. RUIZ-RICO RUIZ, G. "El derecho a una muerte digna desde la perspectiva del Estado Autonómico español. Una especial referencia al caso de la legislación andaluza", en Revista de la Facultad de Ciencias Jurídicas, no 14-15- 2009/10, pp. 275 y ss. SARMIENTO-MEDINA, M. I. VARGAS-CRUZ, S. L, VELÁSQUEZ-JIMÉNEZ, C. vol.07, nº. 02, Rio de Janeiro, 2014. pp.710-758 720
} 


\title{
La Ley Andaluza sobre los Derechos y Garantías de la dignidad de la persona en el proceso de la muerte
}

\author{
Consideraciones previas
}

El art. 55.1 del Estatuto de Autonomía de Andalucía asigna competencia exclusiva a la Comunidad Autónoma en la organización, funcionamiento interno, evaluación, inspección y control de centros y servicios sanitarios, sin perjuicio de lo establecido en la Constitución. Así mismo, el art. 55.2 del Estatuto de Autonomía establece que la Comunidad Autónoma de Andalucía tiene competencias compartidas en materia de sanidad interior y, en particular, sobre la ordenación y ejecución de las medidas destinadas a preservar, proteger y promover la salud pública en todos los ámbitos ${ }^{35}$.

El Estatuto de Autonomía de Andalucía reconoce en su artículo 20.1 el derecho a declarar la voluntad vital anticipada, que deberá respetarse en los términos que establezca la Ley ${ }^{36}$. En el mismo artículo establece en su apartado segundo que todas las personas tienen derecho a recibir un adecuado tratamiento del dolor y cuidados paliativos integrales y a la plena dignidad en el proceso de su muerte. El derecho de acceso a los cuidados paliativos es reiterado por el Estatuto de Autonomía en el art. 22.2.i). Si bien el tratamiento del dolor forma parte de los cuidados paliativos integrales, el Estatuto de Autonomía para Andalucía le concede una especial importancia, por lo que en la presente Ley se desarrolla este derecho de forma integral. Así también, el art. 38 del Estatuto de Autonomía de Andalucía establece que la prohibición de discriminación del art. 14 y los derechos reconocidos en el Capítulo II vinculan a todos los poderes públicos andaluces y, dependiendo de la naturaleza de cada derecho, a los particulares, debiendo ser interpretados en el sentido más favorable a su plena efectividad. Correspondiendo al Parlamento el desarrollo de Leyes que respetarán, en todo momento, el contenido de los mismos establecidos por

M. SIERRA DE JARAmillO, M. (2012) "Problemas y decisiones al final de la vida en pacientes con enfermedad en etapa terminal”, en Revista Salud pública, no 14-(1).

35 Ley Orgánica 2/2007, de 19 de marzo, de reforma del Estatuto de Autonomía de Andalucía. Ver: http://noticias.juridicas.com/base_datos/Admin/lo2-2007.html. Consultado 12-08-2013. Art. 55: Salud, Sanidad y Farmacia: 1. Corresponde a la Comunidad Autónoma la competencia exclusiva sobre organización, funcionamiento interno, evaluación, inspección y control de centros, servicios y establecimientos sanitarios, así como en el marco del art. 149.1.16 de la Constitución la ordenación farmacéutica. Igualmente le corresponde la investigación con fines terapéuticos, sin perjuicio de la coordinación general del Estado sobre esta materia. 2. Corresponde a la Comunidad Autónoma de Andalucía la competencia compartida en materia de sanidad interior y, en particular y sin perjuicio de la competencia exclusiva que le atribuye el artículo 61, la ordenación, planificación, determinación, regulación y ejecución de los servicios y prestaciones sanitarias, sociosanitarias y de salud mental de carácter público en todos los niveles y para toda la población, la ordenación y la ejecución de las medidas destinadas a preservar, proteger y promover la salud pública en todos los ámbitos, incluyendo la salud laboral, la sanidad animal con efecto sobre la salud humana, la sanidad alimentaria, la sanidad ambiental y la vigilancia epidemiológica, el régimen estatutario y la formación del personal que presta servicios en el sistema sanitario público, así como la formación sanitaria especializada y la investigación científica en materia sanitaria. 3. Corresponde a Andalucía la ejecución de la legislación estatal en materia de productos farmacéuticos. 4. La Comunidad Autónoma participa en la planificación y la coordinación estatal en materia de sanidad y salud pública con arreglo a lo previsto en el Título IX.

${ }^{36}$ RODRIGUEZ, A. "Muerte digna y derechos en los Estatutos de Autonomía”, en Autonomía personal, Cuidados paliativos y Derecho a la vida”, en PRESNO LINERA M. A. (Coordinador), Procura, no 1, 201 1, pp. 2 y ss. 
el Estatuto de Autonomía y determinarán las prestaciones y servicios vinculados, en su caso, al ejercicio de estos derechos. Así también, en la Ley 2/1998, de 15 de julio, de salud de Andalucía ${ }^{37}$ se establece en sus apartados 3 y 11 del art. 2 que las actuaciones sobre protección de la salud se inspirarán en los principios de concepción integral de la salud y mejora continua de la calidad de los servicios, con un enfoque especial a la atención personal y a la confortabilidad del paciente y sus familiares ${ }^{38}$.

Se afirma en la Exposición de Motivos de la Ley de derechos y garantías de la dignidad de la persona en el proceso de la muerte de Andalucía ${ }^{39}$ que: "Los avances de la medicina y otras ciencias afines permiten prologan la vida o el mantenimiento de funciones vitales hasta límites insospechados hace pocos años, lo que sumado al envejecimiento de la población y el consiguiente incremento de personas con enfermedades crónicas, hacen que un número creciente de personas con enfermedades degenerativas o irreversibles lleguen a una situación terminal, caracterizada por la incurabilidad de la enfermedad causal, un pronóstico de vida limitado y un intenso sufrimiento personal y familiar, con frecuencia en un contexto de atención sanitaria intensiva altamente tecnificada. Así también, la emergencia del valor de la autonomía personal ha modificado profundamente los valores de la relación clínica, que deben adaptarse ahora a la individualidad de la persona enferma. Por ello, en una sociedad democrática, el respeto a la liberta y autonomía de la voluntad de la persona han de mantenerse durante la enfermedad y alcanzar plenamente al proceso de la muerte" ${ }^{\prime 40}$.

Teniendo en consideración la normativa emanada por parte de distintas instancias internacionales en el ámbito de la salud ${ }^{41}$ y la trascendencia que tiene el ejercicio de los derechos en el ámbito sanitario en la sociedad andaluza, multicultural y diversa, en la que coexisten distintas creencias, valores y preferencias acerca de la muerte y la forma de afrontarla, que son merecedoras del mismo respeto y garantías en su ejercicio, siempre que no se infrinja el ordenamiento jurídico, las Leyes andaluzas ${ }^{42}$ han reconocido y regulado el derecho de la autonomía individual de los pacientes en el ejercicio de los derechos reconocidos a nivel estatal.

\footnotetext{
${ }^{37}$ Ley 2/1998, de 15 de junio, de salud de Andalucía: Ver. http://noticias.juridicas.com/base_datos/CCAA/an-12-1998.html. Consultado el 12-08-2013.

${ }^{38}$ Exposición de Motivos de la Ley 2/2010, de 8 de abril, de Derechos y Garantías de la dignidad de la persona en el proceso de la muerte de Andalucía. Ver: http://noticias.juridicas.com/base_datos/Admin/lo2-2007.t2.html\#a55. Consultado el 12-08-2013.

39 Para más información, ver: LEAL ADORNA, M. M. (2012) "Ley Andaluza de Derechos y Garantías de la Dignidad de la Persona en el Proceso de la Muerte: Sus problemas presentes y futuros”, en Cuestiones de Derecho Eclesiástico del Estado: In Memoriam Ález Seglers, Coordinadores, ROSSELL, J.y GARCÍA GARCÍA, R.

${ }^{40}$ Exposición de Motivos de la Ley 2/2010, de 8 de abril, de Derechos y Garantías de la dignidad de la persona en el proceso de la muerte de Andalucía.

${ }^{41}$ Convenio sobre derechos humanos y biomedicina del Consejo de Europa, el Convenio de Oviedo de 1997, la Declaración Universal de bioética y Derechos Humanos de la Conferencia General de la UNESCO de 19 de octubre de 2005.

${ }^{42}$ Ley 2/1998, de 15 de junio, de salud de Andalucía, como la Ley 14/1986, de 24 de abril General Sanitaria, y la Ley 41/2002, de 14 de noviembre, Básica reguladora de la autonomía del paciente y de derechos y obligaciones en materia de información y documentación clínica.
} 
Siendo conscientes de que todos los seres humanos aspiran a vivir dignamente y que es parte integrante de vida digna, la muerte digna, por lo que, el ordenamiento jurídico está obligado a proteger y concretar este ideal de muerte digna ${ }^{43}$, destacar que sólo goza de consenso, dentro del contenido de la muerte digna, el derecho del paciente a recibir cuidados paliativos integrales y de calidad, no pudiendo afirmarse que exista consenso ético y jurídico en determinadas situaciones, como la de permitir a quien sufre solicitar ayuda para que otra persona termine con su vida ${ }^{44}$.

Otro contenido que goza de consenso en el ámbito de la muerte digna hace referencia al derecho que tienen todas las personas de redactar un documento escrito en el que hagan constar sus deseos y preferencias de tratamientos para el caso eventual del el que no puedan decidir por sí mismas, así como a designar mediante dicho documento a quien tomará decisiones en su lugar, derecho regulado en la Comunidad Autónoma de Andalucía en la Ley $5 / 2003$, de 9 de octubre de Declaración de voluntad vital anticipada ${ }^{45}$, siendo reforzada esta posición por parte del art. 20 del vigente Estatuto de Autonomía de Andalucía ${ }^{46}$.

A pesar de que en el marco legislativo la Ley de 2003 de Declaración de voluntad vital anticipada ha cumplido sobradamente el objetivo propuesto, se ha visto la necesidad de mejorarla. Es por ello que, desde la perspectiva del principio de autonomía de la voluntad de la personas, existen dos cauces o instrumentos principales para hacer posible su dignidad en el proceso de la muerte. El primero, el derecho de la persona a la información clínica, al consentimiento informado y a la toma de decisiones. La segunda, consiste en el derecho de la persona a realizar la declaración de voluntad vital anticipada y a que sea respetada la misma. Se trata de dos derechos que tienen un presupuesto común, el principio de la autonomía de la voluntad, si bien en el consentimiento informado dicha voluntad se manifiesta de presente, es decir, en el momento mismo en que surge la necesidad de la intervención sanitaria, mientras que, en la declaración de voluntad vital anticipada, se anticipa el consentimiento para el caso de que surja esa necesidad.

A partir de aquí, una de las reformas conceptuales que se introducen en el Título II, art. 9.5, de la Ley de derechos y garantías de la dignidad de la persona en el proceso de la muerte es la de incorporar el ámbito de los valores vitales de la persona al contenido de la declaración de voluntad vital anticipada, así como la posibilidad de dar a la ciudadanía mayor accesibilidad a la declaración de voluntad vital anticipada. Si bien en la Ley 5/2003, de 9

\footnotetext{
${ }^{43}$ SARMIENTO-MEDINA, M. I. VARGAS-CRUZ, S. L, VELÁSQUEZ-JIMÉNEZ, C. M. SIERRA DE JARAMILLO, M. (2012) "Problemas y decisiones al final de la vida en pacientes con enfermedad en etapa terminal", en Revista Salud pública, no 14-(1), pp. 116-128.

${ }^{44}$ Exposición de Motivos de la Ley 2/2010, de 8 de abril, de Derechos y Garantías de la dignidad de la persona en el proceso de la muerte de Andalucía.

45 Ley 5/2003, de 9 de octubre, de Declaración de voluntad vital anticipada de Andalucía. Ver. http://noticias.juridicas.com/base_datos/CCAA/an-15-2003.html. Consultado el 12-08-2013.

${ }^{46}$ Ley Orgánica 2/2007, de 19 de marzo, de Reforma del Estatuto de Autonomía de Andalucía. Art. 20-1), 2) y 3): Deberes respecto a las personas que puedan hallarse en situación de incapacidad de hecho. Ver: http://noticias.juridicas.com/base_datos/CCAA/an-12-2010.t3.html\#a20. Consultado el 12-08-2013. 
de octubre, la verificación de la capacidad y requisitos formales de la declaración se realizaba por personal funcionario dependiente de la Consejería de Salud responsable del Registro, la presente Ley prevé que sea personal funcionario público habilitado por la Consejería de Salud el que realice esta función, facilitando de este modo el otorgamiento de la declaración de voluntad vital anticipada en cualquier lugar del territorio de la Comunidad Autónoma de Andalucía y, con ello, la accesibilidad de la ciudadanía al Registro de Voluntades vitales anticipadas.

Otra cuestión fundamental que se ha puesto de manifiesto en la Ley de derechos y garantías de la dignidad de la persona en el proceso de la muerte es la necesidad de mejorar la accesibilidad de la persona a la declaración de voluntad vital anticipada. La información para proceder a realizar la declaración vital anticipada debe ser facilitada por parte de los profesionales sanitarios que participan en la atención sanitaria del paciente, si bien la Ley 5/2003 hace referencia a que los profesionales sanitarios responsables del proceso, como sujetos obligados a consultar en el Registro la constancia del otorgamiento de la declaración de voluntad vital anticipada, se amplía este deber al personal sanitario encargado de la atención sanitaria, reforzado de esta forma la eficacia de la declaración que, además habrá de incorporarse sistemáticamente a la historia clínica para facilitar su acceso a los profesionales.

Es novedosa, así también, la regulación expresa de los deberes de los profesionales sanitarios respecto a los testamento vitales, al establecer la obligación de proporcionar a las personas información acerca de la declaración, de recabar información sobre si se ha otorgado, de consultar, en su caso, en el Registro de voluntades vitales anticipadas para conocer su contenido y el deber de respetar los valores e instrumentos contenidos en el documento.

Otra de las cuestiones que se introducen en la presente Ley respecto a la delimitación de funciones de la persona representante designada por la persona autora de la declaración en relación con lo que se establecía en el art. 3 de la Ley 5/2003, que conectaba su función a la de sustitución en el otorgamiento del consentimiento informado. La práctica ha puesto de manifiesto que los principales problemas de interpretación de la declaración de voluntad anticipada y del papel de la persona representante surge cuando las situaciones clínicas no han sido previstas. Por ello, se ha considerado conveniente concretar más la función del representante, así como los criterios hermenéuticos que pueda tener en cuenta ésta persona. Así, y teniendo en consideración la premisa de que el representante actuará siempre buscando el mayor beneficio de la persona que representa y con respeto a su dignidad personal, se dispone que para las situaciones clínicas no contempladas explícitamente en el documento deberá tener en cuenta tanto los valores vitales recogidos en la declaración, como la voluntad que presuntamente tendrían los pacientes si estuvieran en este momento en situación de capacidad.

Con el fin de preservar y asegurar de forma efectiva la plena dignidad de la persona en el proceso de la muerte, esta Ley no sólo establece y desarrolla los derechos que asisten a las personas en este trance, sino que 
también determina los deberes del personal sanitario que atienden a los pacientes en el proceso de muerte y atribuyen un conjunto de obligaciones para las instituciones sanitarias, públicas o privadas, en orden a garantizar los derechos del paciente. Por ello, se regulan los deberes de los profesionales sanitarios encargados de la atención a personas ante el proceso de la muerte, en lo que se refiere a la información sobre su proceso, de la que deberá quedar constancia en el historial médico, y al respecto de las preferencias de los pacientes en la toma de decisión, ya que se expresen estas a través del consentimiento informado o en forma de testamento vital, estableciéndose para este caso criterios mínimos para la valoración de la incapacidad de hecho de los pacientes.

Se regulan también, los deberes de los profesionales sanitarios respecto de la delimitación de las medidas de soporte vital, con el fin de evitar la denominada obstinación terapéutica y determinar el procedimiento de retirada o no instauración de estas medidas ${ }^{47}$ de forma consensuada entre el equipo asistencial y preservando las intervenciones necesarias para el adecuado confort de la persona en estas circunstancia.

Señala la Exposición de Motivos de la Ley de derechos y garantías de la dignidad de la persona en el proceso de la muerte que es necesario hacer referencia al término "eutanasia" ${ }^{48}$. Si bien etimológicamente el término sólo significa, buena muerte y, en este sentido etimológico, vendría a resumir de excelente manera el ideal de la muerte digna, esta palabra se ha ido cargando de numerosos significados, adherencias emocionales, que la han vuelto imprecisa y necesitada de una nueva definición.

Para deslindar sus diversos significados se han introducido distintos adjetivos como "activa, pasiva, directa, indirecta, voluntaria o involuntaria”. El resultado final de todo ello ha sido que la confusión entre la ciudadanía, profesionales sanitarios, los medios de comunicación y aun, los expertos en bioética o en derecho, no han hecho sino aumentar.

Como un intento de delimitar el significado de la palabra eutanasia existe hoy en día una tendencia creciente a considerar sólo como tal las actuaciones que:

a) producen la muerte del paciente, es decir, que la causan de forma directa e intencionada mediante una relación causa-efecto única e inmediata;

b) se realizan a petición expresa, reiterada en el tiempo, e informada de los pacientes en situación de capacidad;

c) se realizan en un contexto de sufrimiento debido a una enfermedad incurable que los pacientes experimentan como inaceptable y que no ha podido ser mitigada por otros medios, por ejemplo, mediante cuidados paliativos;

\footnotetext{
${ }^{47}$ CHUEVA RODRÍGUEZ, R. "El marco constitucional del final de la propia vida”, en Revista de Derecho Constitucional, n 85 , 2009, pp. 104 y ss.

${ }^{48}$ RUÍZ MIGUEL, A. “Autonomía individual y derecho a la propia muerte”, en Revista Española de Derecho Constitucional, n 89 , 2010 . 
d) y son realizados por profesionales sanitarios que conocen a los pacientes y mantienen con ellos una relación clínica significativa.

Teniendo en consideración estos criterios, las actuaciones que no encajen en los supuestos anteriores no deberían ser etiquetados de eutanasia. El Código Penal vigente no utiliza este término, pero su art. $143.3^{\circ}$ incluye la situación expuesta mediante un subtipo privilegiado para una forma de auxilio o inducción al suicidio ${ }^{49}$.

Destacar también que, el rechazo de tratamiento, la limitación de medidas de soporte vital y la sedación paliativa ${ }^{50}$ no deben ser calificadas como acciones de eutanasia. Estas actuaciones nunca buscan deliberadamente la muerte del paciente, sino aliviar o evitar el sufrimiento, respetar la autonomía de los pacientes y humanizar el proceso de la muerte. Aceptar el derecho de la persona enferma a rechazar una determinada intervención sanitario no es sino mostrar un exquisito respeto a la autonomía de la voluntad personal, a la libertad de cada cual para gestionar su propia biografía asumiendo las secuencias de las decisiones que toma.

En este sentido se pronunció el Dictamen no 90/2007 del Consejo Consultivo de Andalucía ${ }^{51}$ en relación con la petición formulada por una paciente, la Sra. Doña Inmaculada Echeverria, mediante la que solicitaba la suspensión del tratamiento con ventilación mecánica que venía recibiendo en los últimos 10 años en el Hospital San Rafael de Granada. Se afirma en el Dictamen que: “... se trata de una petición amparada por el derecho a rehusar el tratamiento y su derecho a vivir dignamente..." Y que "... Resulta exigible la conducta debida por parte de los profesionales sanitarios para que sea respetado el derecho de la misma a rechazar los medios de soporte vital que se aplican.... El uso inadecuado de medidas de soporte vital, esto es, su aplicación cuando no tienen otro efecto que mantener artificialmente una vida meramente biológica, sin posibilidades reales de recuperación de la integridad funcional de la vida personal, es contraria a la dignidad de la vida humana. Por ello, no iniciar o retirar dichas medidas es algo que sólo aspira a respetar dicha dignidad de forma plena. Facilitar, a aquellas personas en situación terminal que libremente lo deseen, la posibilidad de entrar en la muerte sin sufrimiento, en paz, no puede ser sino otra expresión del respeto a la dignidad del ser humano. Ninguna de estas prácticas puede ser considerada contraria a una ética basada en la idea de dignidad y en el respeto a la Declaración Universal de los Derechos Humanos, antes al contrario, deben ser consideradas buenas prácticas clínicas y actuaciones profesionales plenamente conformes a la legalidad vigente.

Durante los últimos años, distintos casos relacionados con el rechazo de tratamientos, la limitación de medidas de soporte vital o de sedación paliativa han sido motivo de debate en la sociedad andaluza y española. En

\footnotetext{
${ }^{49}$ Exposición de Motivos de la Ley 2/2010, de 8 de abril, de Derechos y Garantías de la dignidad de la persona en el proceso de la muerte de Andalucía.

${ }^{50}$ NADAL, C. e PINCEMIN, I. "Cuidados paliativos: derecho al final de la vida”, en Revista Debate Público. Reflexión de Trabajo Social, año 2, no 4.pp. 1-74.

${ }^{51}$ Ver en: http://www.juntadeandalucia.es/consejoconsultivo/noticias/detalle.jsp?id_noticia=217\&seccion=36\&padre=noticias. Consultado el 12-08-2013. 
ellos se han generado dudas acerca de si las actuaciones de los profesionales habían sido éticamente correctas y conformes a Derecho. A través de la presente Ley se quiere contribuir decisivamente a proporcionar seguridad jurídica a la ciudadanía y a los profesionales sanitarios ${ }^{52}$.

\section{Contenido dela Ley}

La Ley de Derechos y Garantías de la dignidad de la persona en el proceso de la muerte contiene: una Exposición de Motivos y cinco Títulos, en el primero, se regulan las disposiciones generales, seguidamente los derechos de las personas ante el proceso de la muerte, a continuación, se recogen los deberes de los profesionales sanitarios que atienden a pacientes ante el proceso de la muerte, para concluir con los garantías que deben proporcionar las instituciones sanitarias y las infracciones y sanciones.

En el Título primero, se contienen 5 artículos que hacen referencia al objeto, los fines, el ámbito de aplicación, los principios básicos y las definiciones.

Se señala que, es objeto de la Ley, regular el ejercicio de los derechos de la persona durante el proceso de su muerte, los deberes del personal sanitario que atiende a estos pacientes, así como las garantías que las institucionales sanitarias estarán obligadas a proporcionar con respecto a ese proceso. Destacar que en este artículo se contienen los tres grandes apartados que recoge la Ley, los derechos de persona en fase terminal, los deberes de los profesionales sanitarios y las garantías que deberán preservar y proteger las instituciones sanitarias. Los fines que se persiguen con esta Ley son dos:

a) Proteger la dignidad de la persona en el proceso de su muerte, $y$;

b) Asegurar la autonomía de los pacientes y el respeto a su voluntad en el proceso de la muerte, incluyendo la manifestada de forma anticipada mediante el testamento vital.

Se aplicará la Ley en el ámbito de la Comunidad Autónoma de Andalucía, a las personas que se encuentren en el proceso de su muerte o que afronten decisiones relacionadas con dicho proceso, al personal implicado en su atención sanitaria, así como a los centros, servicios y establecimientos sanitarios, tanto públicos como privados, y entidades aseguradoras que presten sus servicios en Andalucía.

Se constituyen en Principios Básicos que inspirarán la Ley los siguientes:

a) La garantía del pleno respeto del derecho a la plena dignidad de la persona en el proceso de la muerte;

b) La promoción de la libertad, la autonomía y la voluntad de la persona, de acuerdo con sus deseos, preferencias, creencias o valores, así como la preservación de su intimidad y confidencialidad;

\footnotetext{
52 Exposición de Motivos de la Ley 2/2010, de 8 de abril, de Derechos y Garantías de la dignidad de la persona en el proceso de la muerte de Andalucía. 
c) La garantía de que el rechazo de un tratamiento por voluntad de la persona, o la interrupción del mismo, no suponga el menoscabo de una atención sanitaria integral y del derecho a la plena dignidad de la persona en el proceso de su muerte;

d) La garantía del derecho de todas las personas a recibir cuidados paliativos integrales y un adecuado tratamiento del dolor en el proceso de su muerte;

e) La igualdad efectiva y la ausencia de discriminación en el acceso a los servicios sanitarios en el proceso de la muerte.

Cuestión trascendental es determinar el contenido de algunos de los términos que se contienen en la Ley, así queremos destacar los contenidos que se contienen y que en muchas ocasiones serán fuente de interpretación a la hora de proceder a aplicar la Ley. Dispone la Ley que se entiende por:

Calidad de vida: Supone la satisfacción individual ante las condiciones objetivas de vida desde los valores y las creencias personales.

Consentimiento informado: De acuerdo con lo que se establece en el art. 3 de la Ley 41/2002, de 14 de noviembre, Básica reguladora de la autonomía del paciente.... supone: "la conformidad libre, voluntarias y consciente de un paciente, manifestada en pleno uso de sus facultades después de recibir la información adecuada, para que tenga lugar una actuación que afecta a su salud".

Cuidados paliativos: Conjunto coordinado de intervenciones sanitarias dirigidas, desde un enfoque integral, a la mejora de la calidad de vida de los pacientes y de sus familias, afrontando los problemas asociados con una enfermedad terminal mediante la prevención y el alivio del sufrimiento, así como la identificación, valoración y tratamiento del dolor y otros síntomas físicos y/o psíquicos.

Declaración de voluntad vital anticipada: De acuerdo con lo dispuesto en el artículo 2 de la Ley 5/2003, de 9 de octubre, de declaración de voluntad vital anticipada, es la manifestación escrita, hecha para ser incorporada al Registro de Voluntades Vitales Anticipadas, por una persona capaz que, consciente y libremente, expresa las opciones e instrucciones que deben respetarse en la atención sanitaria que reciba en el caso de que concurran circunstancias clínicas en las cuales no pueda expresar personalmente su voluntad.

Intervención en el ámbito de la sanidad: De acuerdo con lo dispuesto en el artículo 3 de la Ley 41/2002, de 14 de noviembre, es "toda actuación realizada con fines preventivos, diagnósticos, terapéuticos, rehabilitadores o de investigación”.

Limitación del esfuerzo terapéutico: Retirada o no instauración de una medida de soporte vital o de cualquier otra intervención que, dado el mal pronóstico de la persona en términos de cantidad y calidad de vida futuras, constituye, a juicio de los profesionales sanitarios implicados, algo fútil, que solo contribuye a prolongar en el tiempo una situación clínica carente de expectativas razonables de mejoría. 
Medida de soporte vital: Intervención sanitaria destinada a mantener las constantes vitales de la persona, independientemente de que dicha intervención actúe o no terapéuticamente sobre la enfermedad de base o el proceso biológico, que amenaza la vida de la misma.

Médico o médica responsable: De acuerdo con lo dispuesto en el artículo 3 de la Ley 41/2002, de 14 de noviembre, es "el profesional que tiene a su cargo coordinar la información y la asistencia sanitaria del paciente o del usuario, con el carácter de interlocutor principal del mismo en todo lo referente a su atención e información durante el proceso asistencial, sin perjuicio de las obligaciones de otros profesionales que participan en las actuaciones asistenciales".

Obstinación terapéutica: Situación en la que a una persona, que se encuentra en situación terminal o de agonía y afecta de una enfermedad grave e irreversible, se le inician o mantienen medidas de soporte vital u otras intervenciones carentes de utilidad clínica, que únicamente prolongan su vida biológica, sin posibilidades reales de mejora o recuperación, siendo, en consecuencia, susceptibles de limitación.

Personas en proceso de muerte: Personas que se encuentran en situación terminal o de agonía.

Representante: Persona mayor de edad y capaz que emite el consentimiento por representación de otra, habiendo sido designada para tal función mediante una declaración de voluntad vital anticipada o, de no existir esta, siguiendo las disposiciones legales vigentes en la materia.

Sedación paliativa: Administración de fármacos, en las dosis y combinaciones requeridas, para reducir la conciencia de la persona en situación terminal o de agonía, para aliviar adecuadamente uno o más síntomas refractarios, previo consentimiento informado explícito en los términos establecidos en la Ley.

Síntoma refractario: Aquel que no responde al tratamiento adecuado y precisa, para ser controlado, reducir la conciencia de los pacientes.

Situación de agonía: Fase gradual que precede a la muerte y que se manifiesta clínicamente por un deterioro físico grave, debilidad extrema, trastornos cognitivos y de conciencia, dificultad de relación y de ingesta, y pronóstico vital de pocos días.

Situación de incapacidad de hecho: Situación en la que las personas carecen de entendimiento y voluntad suficientes para gobernar su vida por sí mismas de forma autónoma, sin que necesariamente haya resolución judicial de incapacitación.

Situación terminal: Presencia de una enfermedad avanzada, incurable y progresiva, sin posibilidades razonables de respuesta al tratamiento específico, con un pronóstico de vida limitado y en la que pueden concurrir síntomas intensos y cambiantes que requieran una asistencia paliativa específica.

Testamento vital: Es un sinónimo de declaración de voluntad vital anticipada. 
Valores vitales: Conjunto de valores y creencias de una persona que dan sentido a su proyecto de vida y que sustentan sus decisiones y preferencias en los procesos de enfermedad y muerte.

\section{Derechos de la persona ante el proceso de la muerte}

En el Título II se recogen los Derechos de la persona ante el proceso de la muerte. El primero de los derechos hace referencia a "la información asistencial", derecho que corresponde a las personas que se encuentren en el proceso de muerte o que afronten decisiones relacionadas con dicho proceso y, que recibirán información en los términos establecidos en los art. 4 y 5 de la Ley 41/2002, de 14 de noviembre. También se establece que el paciente puede rechazar voluntaria y libremente la información asistencial que los profesionales implicados en su tratamiento están obligados a dar. En el presente caso se hará ver al paciente la trascendencia del rechazo, y se le solicitará que designen una persona que acepte recibirla y tomar las decisiones en su nombre ${ }^{53}$.

Las personas que se encuentran en el proceso de muerte o que afrontan decisiones relacionadas con dicho proceso tienen derecho a tomar decisiones respecto a las intervenciones sanitarias que les afecten. Toda intervención en este ámbito requiere el previo consentimiento libre y voluntario de los pacientes, una vez que hayan recibido y valorado la información prevista en el art. 6, todo ello, sin perjuicio de lo dispuesto en el art. 11 . Se señala que el consentimiento será verbal por regla general, dejándose en todo caso constancia en la historia clínica, sin perjuicio de lo dispuesto en el art. 8.2 de la Ley $41 / 2002$, de 14 de noviembre ${ }^{54}$.

Los pacientes en fase terminal tienen derecho a rechazar la intervención propuesta por los profesionales sanitarios ${ }^{55}$, tras un proceso de información y decisión, aunque ello pueda poner en peligro su vida. Este rechazo deberá constar por escrito, señalándose que si no puede firmar, firmará en su lugar otra persona que actuará como testigo a su ruego, dejando constancia de su identificación y del motivo que impide la firma por la persona que rechaza la intervención propuesta, constando todo ello en el historial clínico ${ }^{56}$.

También se reconoce el derecho de los pacientes a revocar el consentimiento informado emitido respecto de una intervención concreta, lo que implicará necesariamente la interrupción de dicha intervención.

\footnotetext{
${ }^{53}$ Art. 6 de la Ley 2/2010, de 8 de abril, de Derechos y Garantías de la dignidad de la persona en el proceso de la muerte de Andalucía. Derecho a la información asistencial.

${ }^{54}$ Art. 7 de la Ley 2/2010, de 8 de abril, de Derechos y Garantías de la dignidad de la persona en el proceso de la muerte de Andalucía. Derecho a la toma de decisiones y al consentimiento informado.

${ }^{55}$ CHUEVA RODRÍGUEZ, R. "El marco constitucional del final de la propia vida”, en Revista de Derecho Constitucional, n 85 , 2009, pp. 104 y ss. MARTÍN GÓMEZ, J. A. “Eutanasia: aproximación al tratamiento jurídico de la disponibilidad vital”, en Revista Jurídica de Cataluña, año XCLC, no 3, 1995, pp. 286 y ss. Del mismo autor: "Reflexiones sobre la eutanasia: Una cuestión pendiente del Derecho Constitucional a la vida", en Revista de Derecho Constitucional, no 54, 1998, pp. 109 y ss. ARRUEGO RODRÍGUEZ, G. "El rechazo y la interrupción del tratamiento de soporte vital en el Derecho español", en INDRET, n 2, 2009.

${ }^{56}$ Art. 8 de la Ley 2/2010, de 8 de abril, de Derechos y Garantías de la dignidad de la persona en el proceso de la muerte de Andalucía. Derecho al rechazo y a la retirada de una intervención. Para más información, ver: ARRUEGO, G. "El derecho del paciente a rechazar el tratamiento en la nueva normativa sobre el "proceso de la muerte", en Autonomía personal, cuidados paliativos y Derecho a la vida, PRESNO LINERA, M. A. (Coordinador), Procura, nº 1, 2011, pp. 2 y ss.
} 
Reconociéndose también en este caso que, si la persona no pudiera firmar, firmará en su lugar otra persona que actuará como testigo a su ruego, dejando constancia de su identidad y del motivo que impide la firma de quien revoca su consentimiento informado. Todo ello deberá constar por escrito en la historia clínica ${ }^{57}$.

Sin prejuicio de lo previsto en la Ley 41/2002, de 14 de noviembre, toda persona tiene derecho a formalizar su declaración de voluntad vital anticipada en las condiciones establecidas en la Ley 5/2003, de 9 de octubre, y en el resto de normativa que sea de aplicación. Inscrita en el Registro de Voluntades Anticipadas de Andalucía, la declaración de voluntad anticipada se incorporará a la historia clínica, y se tendrán en consideración los procedimientos previstos para el acceso a las instrucciones previas anticipadas emitidas por parte del paciente de otras Comunidades Autónomas y que estén inscritas en el Registro Nacional de Instrucciones previas, de acuerdo con lo que se establece en el Real Decreto 124/2007, de 2 de febrero, por el que se regula el Registro Nacional de Instrucciones Previas y el correspondiente fichero automatizado de datos de carácter personal. La declaración de voluntad anticipada se inscribirá en el Registro Nacional y si, en la declaración de voluntad vital anticipada se designa a una persona representante, esta actuará siempre buscando el mayor beneficio y el respeto a la dignidad de la persona a la que representa. Siempre se velará para que, en las situaciones clínicas contempladas en la declaración, se cumplan las instrucciones que la persona a la que represente haya dejado establecidas. La toma de decisiones en las situaciones clínicas no contempladas explícitamente en la declaración de voluntad vital anticipada, a fin de presumir la voluntad que tendría la persona si estuviera en ese momento en situación de capacidad, quien la represente tendrá en cuanta los valores u opciones vitales recogidos en la citada declaración. Concluye señalando que, la persona interesada podrá determinar las funciones de la persona representante, quien deberá atenerse a las mismas ${ }^{58}$.

Por lo que concierne a los derechos de las personas en situación de incapacidad respecto a la información, la toma de decisiones y el consentimiento informado, se establece en el art. 10 que: Cuando la persona que se halla bajo atención médica esté en situación de incapacidad de hecho, a criterio de su médico o médica responsable, tanto la recepción de la información, como la prestación del consentimiento y, en su caso, la elección del domicilio para recibir cuidados paliativos integrales, a que se refiere el art. 12.2 se realizará, por este orden, por la persona designada específicamente a tal fin en la declaración de voluntad vital anticipada, por la persona que actúe como representante legal, por el cónyuge o persona vinculada por análoga relación de afectividad, por los familiares de grado más próximo y dentro del mismo grado el de mayor edad, sin perjuicio de

\footnotetext{
${ }^{57}$ Art. 8 de la Ley 2/2010, de 8 de abril, de Derechos y Garantías de la dignidad de la persona en el proceso de la muerte de Andalucía. Derecho al rechazo y a la retirada de una intervención.

${ }^{58}$ Art. 9 de la Ley 2/2010, de 8 de abril, de Derechos y Garantías de la dignidad de la persona en el proceso de la muerte de Andalucía. Derecho a realizar la declaración vital anticipada.
} 
lo que pudiera decidir la autoridad judicial competente conforme a la legislación procesal ${ }^{59}$. Si el paciente está incapacitado judicialmente se estará a lo dispuesto en la sentencia judicial de incapacitación, salvo que en ella no exista prohibición o limitación expresa sobre la recepción de información o la prestación del consentimiento informado, situación en la cual el médico o la médica responsable valorará la capacidad de hecho de los mismos, en la forma establecida en el art. $20^{60}$. Esta situación de incapacidad no obsta para que los pacientes sean informados y participen en el proceso de la toma de decisiones de modo adecuado a su grado de discernimiento ${ }^{61}$. Finalmente, se afirma que, el ejercicio de los derechos de los pacientes que se encuentren en situación de incapacidad se hará siempre buscando su mayor beneficio y el respeto a su dignidad personal. Para la interpretación de la voluntad de los pacientes se tendrán en cuenta tanto sus deseos expresados previamente, como los que hubieran formulado presuntamente de encontrarse ahora en situación de incapacidad ${ }^{62}$.

¿Qué se entiende por incapacidad de hecho? Se dispone en la Ley que, estaremos ante una situación de incapacidad de hecho cuando las personas carecen de entendimiento y voluntad suficiente para gobernar su vida por sí mismas de forma autónoma, sin que necesariamente haya resolución judicial de incapacitación.

También se contienen los derechos de los pacientes menores de edad en el art. 11, en el que se establece que: "Todo paciente menor de edad tiene derecho a recibir información sobre su enfermedad e intervenciones sanitarias propuestas, de forma adaptada a su capacidad de comprensión". También tienen derecho a que su opinión sea escuchada, "siempre que tengan doce años cumplidos, de conformidad a lo que se establece en la Ley 41/2002, de 14 de noviembre, en su art. 9.3.c)"63. Cuando los pacientes menores de edad no sean capaces intelectual ni emocionalmente de entender el alcance de la intervención sanitaria propuesta, el otorgamiento del consentimiento informado corresponderá a las personas que sean sus representantes legales, de acuerdo con lo que se establece en el art. 9.3.c) de la Ley 41/2002, de 14 de noviembre ${ }^{64}$. Cuando la persona menor esté emancipada o con dieciséis años cumplidos prestará por sí misma el consentimiento, si bien sus padres o representantes legales serán informados y su opinión será tenida en cuenta para la toma de decisiones finales correspondientes, de conformidad a lo establecido en el art. 11.3 y en el art. 9.3.c) de la Ley 41/2002, de 14 de noviembre. Así también, las personas menores emancipadas o con dieciséis años cumplidos tendrán derecho a

\footnotetext{
${ }^{59}$ Art. 10.1 de la Ley 2/2010, de 8 de abril, de Derechos y Garantías de la dignidad de la persona en el proceso de la muerte de Andalucía.

${ }^{60}$ Art. 10.2 de la Ley 2/2010, de 8 de abril, de Derechos y Garantías de la dignidad de la persona en el proceso de la muerte de Andalucía.

${ }^{61}$ Art. 10.3 de la Ley 2/2010, de 8 de abril, de Derechos y Garantías de la dignidad de la persona en el proceso de la muerte de Andalucía.

${ }^{62}$ Art. 10.4 de la Ley 2/2010, de 8 de abril, de Derechos y Garantías de la dignidad de la persona en el proceso de la muerte de Andalucía.

${ }^{63}$ Art. 11.1 de la Ley 2/2010, de 8 de abril, de Derechos y Garantías de la dignidad de la persona en el proceso de la muerte de Andalucía.

${ }^{64}$ Art. 11.2 de la Ley 2/2010, de 8 de abril, de Derechos y Garantías de la dignidad de la persona en el proceso de la muerte de Andalucía.
} 
revocar el consentimiento informado y a rechazar la intervención que les sea propuesta por profesionales sanitarios, en los términos previstos en el art. $8^{65}$. En cualquier caso, el proceso de atención a las personas menores de edad respetará las necesidades especiales de éstas y se ajustará a lo dispuesto o establecido en la normativa vigente $^{66}$.

Los pacientes tienen derecho a recibir cuidados paliativos integrales y a la elección del domicilio para recibirlos. Este derecho corresponde a toda persona que se encuentra en situación terminal o de agonía. Los pacientes en situación terminal o de agonía, si así lo desean, tienen derecho a que se les proporcionen en el domicilio que designen en el territorio de la Comunidad Autónoma de Andalucía los cuidados paliativos que precisen, siempre que no esté contraindicado ${ }^{67}$.

¿Qué se entiende por situación terminal o de agonía y cuidados paliativos integrales? Estaremos en situación de agonía cuando el paciente esté en fase gradual que precede a la muerte y que se manifiesta clínicamente por su deterioro físico grave, debilidad extrema, trastornos cognitivos y de conciencia, dificultad de relación y de ingesta, y pronóstico vital de pocos días. En situación terminal, cuando, en presencia de una enfermedad avanzada, incurable y progresiva, sin posibilidades razonables de respuesta al tratamiento específico, con un pronóstico de vida limitado y en la que pueden concurrir síntomas intensos y cambiantes que requieren una asistencia paliativa vital anticipada. Los cuidados paliativos integrales suponen el conjunto coordinado de intervenciones sanitarias dirigidas, desde un enfoque integral, a la mejora de la calidad de vida de los pacientes y de sus familiares, afrontando los problemas asociados con una enfermedad terminal mediante la prevención y el alivio del sufrimiento, así como la identificación, valoración y tratamiento del dolor y otros síntomas físicos y/o psíquicos.

El derecho al tratamiento del dolor de los pacientes supone el derecho que ostentan a recibir la atención idónea que prevenga y alivie el dolor, incluida la sedación y si el dolor es refractario al tratamiento específico ${ }^{68}$.

Considera la Ley que la sedación paliativa supone la administración de fármacos, en las dosis y combinaciones requeridas, para reducir la conciencia de la persona en situación terminal o de agonía, para aliviar adecuadamente uno o más síntomas refractarios, previo consentimiento informado explícito en los términos

\footnotetext{
${ }^{65}$ Art. de la Ley 2/2010, de 8 de abril, de Derechos y Garantías de la dignidad de la persona en el proceso de la muerte de Andalucía.

${ }^{66}$ Art. 11.4 de la Ley 2/2010, de 8 de abril, de Derechos y Garantías de la dignidad de la persona en el proceso de la muerte de Andalucía.

${ }^{67}$ Art. 12.1 y 2 de la Ley 2/2010, de 8 de abril, de Derechos y Garantías de la dignidad de la persona en el proceso de la muerte de Andalucía.

${ }^{68}$ Art. 13.1 de la Ley 2/2010, de 8 de abril, de Derechos y Garantías de la dignidad de la persona en el proceso de la muerte de Andalucía.
} 
establecidos en la Ley. Por su parte, se consideran síntomas refractarios a aquellos que no responden al tratamiento adecuado y preciso, para ser controlados, reducir la conciencia de los pacientes ${ }^{69}$.

Los pacientes tienen derecho a la administración de la sedación paliativa cuando se encuentren en situación terminal o de agonía, cuando así lo precisen ${ }^{70}$. Se entiende que el paciente está en situación terminal cuando, en presencia de una enfermedad avanzada, incurable y progresiva, sin posibilidades razonables de respuesta al tratamiento específico, con un pronóstico de vida limitado y en la que pueden concurrir síntomas intensos y cambiantes que requieran una asistencia paliativa específica.

Los pacientes ante el proceso de muerte tienen derecho a que se preserve su intimidad personal y familiar y a la protección de todos los datos relacionados con su atención sanitaria ${ }^{71}$, así como, al derecho al acompañamiento, en los términos expresados en el art. 23 y siempre que la asistencia se preste en régimen de internamiento en un centro sanitario, los pacientes, ante el proceso de muerte tienen derecho a: a) disponer, si así lo desean, de acompañamiento familiar, b) y a recibir, cuando así lo soliciten, el auxilio espiritual de acuerdo con sus convicciones y creencias $^{72}$.

\section{Deberes de los profesionales sanitarios}

En el Título III de la Ley se contienen "Los deberes de los profesionales sanitarios que atienden a pacientes ante el proceso de muerte". El primero de los deberes será el respeto a la información clínica, obligación que corresponde al médico o médica responsable de cada paciente, que deberá garantizar el cumplimiento del derecho a la información que se establece en el art. $6^{\circ}$ de la Ley $^{73}$.

Establece la Ley que será médico o médica responsable, en base a lo que se establece en el art. 3 de la Ley 41/2002, de 14 de noviembre, el profesional que tiene a su cargo coordinar la información y la asistencia sanitaria del paciente o del usuario, con el carácter de interlocutor principal del mismo en todo lo referente a su atención e información durante el proceso asistencial, sin perjuicio de las obligaciones de otros profesionales que participan en las actuaciones asistenciales.

\footnotetext{
${ }^{69}$ Art. 5: Definiciones de la Ley 2/2010, de 8 de abril, de Derechos y Garantías de la dignidad de la persona en el proceso de la muerte de Andalucía.

${ }^{70}$ Art, 14 de la Ley 2/2010, de 8 de abril, de Derechos y Garantías de la dignidad de la persona en el proceso de la muerte de Andalucía.

${ }^{71}$ Art. 15 de la Ley 2/2010, de 8 de abril, de Derechos y Garantías de la dignidad de la persona en el proceso de la muerte de Andalucía.

${ }^{72}$ Art. 16 de la Ley 2/2010, de 8 de abril, de Derechos y Garantías de la dignidad de la persona en el proceso de la muerte de Andalucía.

${ }^{73}$ Art. 17.1 de la Ley 2/2010, de 8 de abril, de Derechos y Garantías de la dignidad de la persona en el proceso de la muerte de Andalucía.
} 
Se afirma, así también que, el resto de profesionales sanitarios que atienden a los pacientes durante el proceso asistencial, o les apliquen una intervención concreta, también tienen la obligación de facilitarles información clínica en función de su grado de responsabilidad y participación en el proceso de atención sanitaria. Estos profesionales (médico o médica responsable y aquellos otros profesionales sanitarios que participan en la atención del paciente) dejarán constancia en la historia clínica de que dicha información fue proporcionada a los pacientes y suficientemente comprendida por estos ${ }^{74}$.

Por lo que respecta a la toma de decisiones clínicas, el médico o médica responsable, antes de proponer cualquier intervención sanitaria a una persona en proceso de su muerte, deberá asegurarse de que la misma está clínicamente indicada, elaborando su juicio clínico al respecto basándose en el estado de la ciencia, en la evidencia científica disponible, en su saber profesional y en el estado clínico, gravedad y pronóstico de la persona afectada. En el caso de que este juicio profesional concluya en la indicación de una intervención sanitaria, someterá entonces la misma al consentimiento libre y voluntario de la persona, que podrá aceptar la intervención propuesta, elegir libremente entre las opciones clínicas disponibles o rechazarla, en los términos previsto en la presente Ley y en la Ley 41/2002, de 14 de noviembre ${ }^{75}$.

Todos los profesionales sanitarios implicados en la atención de los pacientes tienen la obligación de respetar los valores, creencias y preferencias de los mismos en la toma de decisiones clínicas, en los términos previstos en la presente Ley, en la Ley 41/2002 de 14 de noviembre, en la Ley 5/2003, de 9 de octubre, y en sus respectivas normas de desarrollo, debiendo abstenerse de imponer criterios de actuación basados en sus propias creencias y convicciones personales, morales, religiosas o filosóficas ${ }^{76}$.

Así también, los profesionales sanitarios deberán respetar la declaración de voluntad anticipada realizada por parte de los pacientes. Por ello, están obligados estos profesionales sanitarios a proporcionar, a las personas que se la soliciten, información acerca del derecho a formular la declaración de voluntad vital anticipada. Si el paciente se encuentra en situación de incapacidad de hecho, los profesionales sanitarios procederán de acuerdo con lo que se establece en el art. 9.2 de la Ley 5/2003, de 9 de octubre ${ }^{77}$. Además, éstos profesionales deberán respetar los valores e instrucciones contenidas en la declaración de voluntad vital anticipada, en los términos

\footnotetext{
${ }^{74}$ Art. 17.2 y 3 de la Ley 2/2010, de 8 de abril, de Derechos y Garantías de la dignidad de la persona en el proceso de la muerte de Andalucía.

${ }^{75}$ Art. 18.1 de la Ley 2/2010, de 8 de abril, de Derechos y Garantías de la dignidad de la persona en el proceso de la muerte de Andalucía.

${ }^{76}$ Art. 18.2 de la Ley 2/2010, de 8 de abril, de Derechos y Garantías de la dignidad de la persona en el proceso de la muerte de Andalucía.

${ }^{77}$ Art. 19.1 y 2 de la Ley 2/2010, de 8 de abril, de Derechos y Garantías de la dignidad de la persona en el proceso de la muerte de Andalucía.
} 
previstos en la presente Ley, en la Ley 41/2002, de 14 de noviembre, y en la Ley 5/2003, de 9 de octubre, y en sus respectivos desarrollos ${ }^{78}$.

El médico o médica responsable tiene el deber, respecto a las personas que puedan hallarse en situación de incapacidad de hecho, de valorar si la persona que se halla bajo atención médica pudiera encontrarse en una situación de incapacidad de hecho que le impidiera decidir por si misma. Esta valoración debe constar adecuadamente en la historia clínica. Para determinar la situación de incapacidad de hecho se evaluarán, entre otros factores que se estimen clínicamente convenientes, los siguientes aspectos:

- Si tiene dificultad para comprender la información que se le suministra,

- Si retiene defectuosamente dicha información durante el proceso de toma de decisiones,

- Si no utiliza la información de forma lógica durante el proceso de toma de decisiones,

- Si falla en la apreciación de las posibles consecuencias de las diferentes alternativas,

Para valorar estos criterios se podrá contar con la opinión de otros profesionales implicados directamente en la atención del paciente y se podrá consultar a la familia con objeto de conocer su opinión ${ }^{79}$.

Establecida la situación de incapacidad de hecho, el médico o médica responsable deberá hacer constar en la historia clínica los datos de quien deba actuar por la persona en situación de incapacidad, conforme a lo previsto en el art. 10.1 de la presente $\mathrm{Ley}^{80}$.

\section{Garantías que deben proporcionar las Instituciones sanitarias}

Finalmente, en el Título IV se contienen las Garantías que deben proporcionar las instituciones sanitarias, debiendo garantizar a los pacientes todos sus derechos, el acompañamiento, el apoyo a la familia y personas cuidadoras, el asesoramiento en cuidados paliativos, la estancia en habitación individual para las personas en situación terminal y la creación de Comités de ética asistencial ${ }^{81}$.

La administración sanitaria, el personal implicado en la atención de los pacientes en el proceso de muerte, o que afronten decisiones relacionadas con dicho proceso, los centros, servicios y establecimiento sanitarios, tanto públicos como privados, y las entidades aseguradoras que presten sus servicios en Andalucía, deberán garantizar, en el ámbito de sus respectivas competencias, el ejercicio de los derechos establecidos en el

\footnotetext{
${ }^{78}$ Art. 19.3 de la Ley 2/2010, de 8 de abril, de Derechos y Garantías de la dignidad de la persona en el proceso de la muerte de Andalucía.

${ }^{79}$ Art. 20.1 y 2 de la Ley 2/2010, de 8 de abril, de Derechos y Garantías de la dignidad de la persona en el proceso de la muerte de Andalucía.

${ }^{80}$ Art. 20.3 de la Ley 2/2010, de 8 de abril, de Derechos y Garantías de la dignidad de la persona en el proceso de la muerte de Andalucía.

${ }^{81}$ Artículos 22 a 27 de la Ley 2/2010, de 8 de abril, de Derechos y Garantías de la dignidad de la persona en el proceso de la muerte de Andalucía. 
Título II de la presente Ley. Así también, las instituciones sanitarias responsables de la atención directa a los pacientes deberán arbitrar los medios para que los derechos de estos no se vean mermados en ningún caso o eventualidad, incluida la negativa o ausencia del profesional o la profesional, así como cualquier otra causa sobrevenida ${ }^{82}$.

Los centros e instituciones sanitarias facilitarán al ciudadano o ciudadana en proceso de muerte el acompañamiento familiar, compatibilizando este con el conjunto de medidas sanitarias necesarias para ofrecer una atención de calidad a los pacientes ${ }^{83}$. Así también, facilitarán, a petición de los pacientes, de las personas que sean sus representantes o de sus familiares, el acceso de aquellas personas que les puedan proporcionar auxilio espiritual, conforme a sus convicciones y creencias procurando, en todo caso, que las mismas no interfieran con las actuaciones del equipo sanitario ${ }^{84}$.

Se deberá prestar apoyo y asistencia a las personas cuidadoras y familias de pacientes en proceso de muerte, tanto en su domicilio, como en los centros sanitarios por parte de los centros e instituciones sanitarias. Así también, prestaran una atención en el duelo a la familia y a las personas cuidadoras y promoverán medidas para la aceptación de la muerte de un ser querido y la prevención del duelo complicado ${ }^{85}$.

Se garantizará información suficiente en relación con los cuidados paliativos a los pacientes en proceso de muerte sobre su estado de salud y sobre los objetivos de sus cuidados paliativos que recibirán durante su proceso, de acuerdo con sus necesidades y preferencias ${ }^{86}$.

Los pacientes en situación terminal, también tendrán derecho en los centros e instituciones sanitarias a ser atendidos en régimen de hospitalización a una habitación individual durante su estancia, con el nivel de confort e intimidad que requiere su estado de salud, pudiendo estar acompañados los pacientes de forma permanente por su familiar o allegado ${ }^{87}$.

Finalmente señala, en relación con los Comités de ética asistencial que, Todo centro sanitario o institución dispondrá o, en su caso, estará vinculado a un Comité de ética asistencial, con funciones de

\footnotetext{
${ }^{82}$ Art. 22 de la Ley 2/2010, de 8 de abril, de Derechos y Garantías de la dignidad de la persona en el proceso de la muerte de Andalucía.

${ }^{83}$ La libertad del paciente y el derecho a no tolerar injerencias de las administraciones sanitarias, ver: ROMEO CASABONA, C. M. El derecho y la bioética ante los límites de la vida humana, 1994. TOMÁS-VALIENTE LANUZA C. La disponibilidad de la propia vida en el Derecho Penal, 1999. De la misma autora: "La disponibilidad de la propia vida: aspectos constitucionales", en El derecho a la vida, Tribunal Constitucional-CEPC, 2003.

${ }^{84}$ Art. 23.1 y 2 de la Ley 2/2010, de 8 de abril, de Derechos y Garantías de la dignidad de la persona en el proceso de la muerte de Andalucía.

${ }^{85}$ Art. 24.1 y 2 de la Ley 2/2010, de 8 de abril, de Derechos y Garantías de la dignidad de la persona en el proceso de la muerte de Andalucía.

${ }^{86}$ Art, 25 de la Ley 2/2010, de 8 de abril, de Derechos y Garantías de la dignidad de la persona en el proceso de la muerte de Andalucía.

${ }^{87}$ Art. 26 de la Ley 2/2010, de 8 de abril, de Derechos y Garantías de la dignidad de la persona en el proceso de la muerte de Andalucía.
} 
asesoramiento en los casos de decisiones clínicas que plantean conflictos éticos, que serán acreditados por la Conserjería competente en materia de salud. Los informes y dictámenes emitidos por el Comité en ningún caso sustituirán las decisiones que tengan que adoptar los profesionales sanitarios. Si existiese discrepancia entre los profesionales sanitarios y los pacientes o, en su caso, con quienes ejerciten sus derechos, o entre estos y las instituciones sanitarias, en relación con la atención sanitaria prestado en el proceso de muerte, que no se hayan podido resolver mediante acuerdo entre las partes implicadas, se solicitará asesoramiento al Comité ético correspondiente, que podrá proponer alternativas o soluciones éticas a aquellas decisiones clínicas controvertidas. Las personas que integran estos Comités de ética están obligadas a guardar secreto sobre el contenido de sus deliberaciones y a proteger la confidencialidad de los datos personales que, sobre profesionales sanitarios, pacientes, familiares y personas allegadas hayan podido conocer en su condición de miembro del Comité. La composición, funcionamiento y procedimiento de acreditación de los Comités se establecerán reglamentariamente ${ }^{88}$.

\section{Infracciones y sanciones}

Tiene previsto, también, en el Título $V$ una serie de infracciones y sanciones que se desarrollaran en el ejercicio de la potestad reglamentaría, distintas sanciones administrativas, previa instrucción del oportuno expediente, sin perjuicio de las responsabilidades civiles, penales o de otro índole en las que pudieran incurrir, aquellas personas físicas o jurídicas que, por acción u omisión, hubiesen participado en las mismas mediante dolo, culpa o negligencia ${ }^{89}$.

Se establecen distintos niveles de infracciones, leves ${ }^{90}$, graves ${ }^{91}$ y muy graves ${ }^{92}$, estableciéndose las sanciones ${ }^{93} \mathrm{y}$ los órganos competentes para aplicarlas ${ }^{94}$.

Concluye la Ley con Disposiciones Adicionales, Transitorias y Finales en los que se contienen: la Evaluación de la Ley, su Difusión, los Cuidados paliativos, la Consulta del Registro de Voluntades vitales

\footnotetext{
${ }^{88}$ Art. 27 de la Ley 2/2010, de 8 de abril, de Derechos y Garantías de la dignidad de la persona en el proceso de la muerte de Andalucía.

${ }^{89}$ Art. 28 de la Ley 2/2010, de 8 de abril, de Derechos y Garantías de la dignidad de la persona en el proceso de la muerte de Andalucía.

${ }^{90}$ Art. 29 de la Ley 2/2010, de 8 de abril, de Derechos y Garantías de la dignidad de la persona en el proceso de la muerte de Andalucía.

${ }^{91}$ Art. 30 de la Ley 2/2010, de 8 de abril, de Derechos y Garantías de la dignidad de la persona en el proceso de la muerte de Andalucía.

${ }^{22}$ Art. 31 de la Ley 2/2010, de 8 de abril, de Derechos y Garantías de la dignidad de la persona en el proceso de la muerte de Andalucía.

${ }^{93}$ Art. 32 de la Ley 2/2010, de 8 de abril, de Derechos y Garantías de la dignidad de la persona en el proceso de la muerte de Andalucía.

${ }^{94}$ Art. 33 de la Ley 2/2010, de 8 de abril, de Derechos y Garantías de la dignidad de la persona en el proceso de la muerte de Andalucía.
} 
anticipadas, la Modificación de la Ley 2/1998, de 15 de junio, de salud de Andalucía, de la Modificación de la Ley 5/2003, de 9 de octubre, de Declaración de voluntad vital anticipada, de los Comités de Ética Asistencial y del Desarrollo reglamentario de la presente Ley.

\section{La Ley Aragonesa de Derechos y Garantías de la dignidad de la persona en el proceso de morir y de la muerte}

\section{Consideraciones previas}

El art. 149.1.16 de la Constitución atribuye al Estado la competencia exclusiva en materia de bases y coordinación general de la sanidad. En su artículo 43, reconoce el derecho a la protección de la salud y atribuye a los poderes públicos la organización y tutela de la salud pública, a través de medidas preventivas y de las prestaciones y servicios necesarios.

En el ámbito autonómico, el artículo 71.55a del Estatuto de Autonomía de Aragón ${ }^{95}$, aprobado por Ley Orgánica 5/2007, de 20 de abril, confiere a la Comunidad Autónoma la competencia exclusiva en materia de sanidad y salud pública.

Asimismo, el artículo 6.1 del Estatuto de Autonomía de Aragón ${ }^{96}$ indica que los derechos y libertades de los aragoneses y aragonesas son los reconocidos en la Constitución, los incluidos en la Declaración Universal de Derechos Humanos y en los demás instrumentos internacionales de protección de los mismos suscritos o ratificados por España, así como los establecidos en el ámbito de la Comunidad Autónoma por el propio Estatuto. De igual manera, el apartado segundo de dicho artículo 6 indica que los poderes públicos aragoneses están vinculados por estos derechos y libertades y además deben velar por su protección y respeto, así como promover su pleno ejercicio ${ }^{97}$.

Entre los derechos establecidos tanto en la Constitución (artículo 43) como en el Estatuto de Autonomía de Aragón (artículo 14), figura el derecho a la protección de la salud ${ }^{98}$. En concreto, el apartado

\footnotetext{
${ }^{55}$ Ley Orgánica 5/2007, de 20 de abril, de Reforma del Estatuto de Autonomía de Aragón. Art. 71: En el ámbito de las competencias exclusivas, la Comunidad Autónoma de Aragón ejercerá la potestad legislativa, la potestad reglamentaria, la función ejecutiva y el establecimiento de políticas propias, respetando lo dispuesto en los artículos 140 y 149.1 de la Constitución. Corresponde a la Comunidad Autónoma la competencia exclusiva en las siguientes materias: apartado 55: Sanidad y salud pública, en especial, la organización, el funcionamiento, la evaluación, la inspección y el control de centros, servicios y establecimientos sanitarios. La Comunidad Autónoma participará, de acuerdo con el Estado, en la planificación y la coordinación estatal en lo relativo a sanidad y salud pública. Ver: http://noticias.juridicas.com/base_datos/Admin/lo5-2007.html. Consultado el 13-082013.

${ }^{96}$ Art. 6.1 del Estatuto de autonomía de Aragón: “Derechos y libertades”. Los derechos y libertades de los aragoneses y aragonesas son los reconocidos en la Constitución, los incluidos en la Declaración Universal de Derecho Humanos y en los demás instrumentos internacionales de protección de los mismos suscritos o ratificados por España, así como los establecidos en el ámbito de la Comunidad Autónoma por el presente Estatuto.

${ }^{97}$ Art. 6.2 del Estatuto de Autonomía de Aragón.

${ }^{98}$ Art. 14 del Estatuto de Autonomía de Aragón.
} 
segundo de este último precepto afirma que los poderes públicos aragoneses garantizarán la existencia de un sistema sanitario público desarrollado desde los principios de universalidad y calidad, una asistencia sanitaria digna, con información suficiente al paciente sobre los derechos que le asisten como usuario. $Y$ en ese mismo artículo 14, en su apartado 4, se establece que todas las personas podrán expresar su voluntad, incluso de forma anticipada, sobre las intervenciones y tratamientos médicos que desean recibir ${ }^{99}$.

Los derechos reconocidos en el Capítulo I del Título I del Estatuto de Autonomía vinculan a todos los poderes públicos aragoneses y, dependiendo de la naturaleza de cada derecho, a los particulares, debiendo ser interpretados en el sentido más favorable a su plena efectividad.

Las Cortes de Aragón deben aprobar las correspondientes Leyes de desarrollo, que respetarán, en todo caso, el contenido de los mismos establecido por el Estatuto y determinarán las prestaciones y servicios vinculados, en su caso, al ejercicio de estos derechos.

En el ámbito normativo de la Comunidad Autónoma de Aragón, la Ley 6/2002, de 15 de abril, de Salud de Aragón, dispone en el apartado a) de su artículo 2, entre otros principios rectores, que las actuaciones sobre protección de la salud se inspirarán en el principio de concepción integral de la salud ${ }^{100}$.

El ejercicio de este derecho tiene especial trascendencia en la sociedad aragonesa, multicultural y diversa, en la que coexisten distintas creencias, valores y preferencias acerca de la muerte y de la forma de afrontarla, que merecen igual respeto y garantía de su libre ejercicio, siempre que no se infrinja lo establecido en el ordenamiento jurídico. Tanto la Ley 14/1986, de 24 de abril, General de Sanidad, como la Ley 6/2002, de 15 de abril, de Salud de Aragón, han reconocido y regulado el derecho a la autonomía individual de los pacientes con respecto a su estado de salud. Sin embargo, la frecuencia cada vez mayor de situaciones complejas relacionadas con la capacidad de decisión sobre la propia vida y sobre la aplicación o no de determinados tratamientos, que han motivado un amplio debate social, refleja la conveniencia de abordar de forma específica la regulación de los derechos de quienes afrontan el proceso de su muerte, con el fin de preservar la dignidad de la persona en ese trance, respetar su autonomía y garantizar el pleno ejercicio de sus derechos.

\footnotetext{
${ }^{99}$ Art. 14 del Estatuto de Autonomía de Aragón: Derecho a la salud: 1. Todas las personas tienen derecho a acceder a los servicios públicos de salud, en condiciones de igualdad, universalidad y calidad, y los usuarios del sistema público de salud tienen de recho a la libre elección de médico y centro sanitario, en los términos que establecen las leyes. 2. Los poderes públicos aragoneses garantizarán la existencia de un sistema sanitario público desarrollado desde los principios de universalidad y calidad, y una asistencia sanitaria digna, con información suficiente al paciente sobre los derechos que le asisten como usuario. 3. Los poderes públicos aragoneses velarán especialmente por el cumplimiento del consentimiento informado. 4. Todas las personas podrán expresar su voluntad, incluso de forma anticipada, sobre las intervenciones y tratamientos médicos que desean recibir, en la forma y con los efectos previstos en las Leyes.

${ }^{100}$ Art. 2 de la Ley 6/2002, de 15 de abril, de Salud de Aragón: art. 2, "Principios rectores": apartado a): Concepción integral de la salud, incluyendo actuaciones hacía todos los factores determinantes de la misma en los campos de la promoción, prevención, asistencia, rehabilitación e integración social. Ver: http://noticias.juridicas.com/base_datos/CCAA/ar-16-2002.t1.html\#a2. Consultado el 13-08-2013.
} 
Mediante la presente Ley, en el marco de lo dispuesto en el Estatuto de Autonomía para Aragón, se procede al desarrollo del artículo 14 del Estatuto de Autonomía de Aragón, en relación con su artículo 12.1, reflejando los contenidos éticos de una regulación normativa sobre la dignidad de las personas ante el proceso de morir y de la muerte.

Todos los seres humanos tienen derecho a vivir dignamente. El ordenamiento jurídico trata de concretar y simultáneamente proteger este derecho. Pero la muerte también forma parte de la vida. Morir constituye el acto final de la biografía personal de cada ser humano y no puede ser separada de aquella como algo distinto. Por tanto, el imperativo de la vida digna alcanza también a la muerte. Una vida digna requiere una atención digna en la etapa final de la vida y una muerte digna.

El derecho a una vida humana digna no se puede truncar con una muerte indigna. El ordenamiento jurídico está, por tanto, llamado también a concretar y proteger este ideal de la muerte digna.

La dimensión concreta de este ideal y los derechos que generan han sido motivo de debate en los últimos años, no sólo en nuestro país, en nuestra Comunidad Autónoma, sino en el mundo entero. Sin embargo, hoy en día puede afirmarse que existe un consenso ético y jurídico bastante consolidado en torno a algunos de los contenidos y derechos del ideal de la buena muerte, sobre los que inciden los artículos de la presente Ley.

Entre los contenidos claves del ideal de muerte digna que gozan de consenso se encuentra el derecho de los pacientes a recibir cuidados paliativos integrales de alta calidad, habiéndose reconocido este derecho en distintas Recomendaciones de la Asamblea Parlamentaria del Consejo de Europa ${ }^{101}$.

En cambio, no puede afirmarse que exista consenso ético y jurídico en determinadas situaciones como la de permitir al paciente que solicite ayuda para que otro termine con su vida ${ }^{102}$.

La presente Ley no contempla la regulación de la «eutanasia». Por el contrario, el rechazo de tratamiento, la limitación de medidas de soporte vital y la sedación paliativa no deben ser calificadas como acciones de eutanasia. Dichas actuaciones nunca buscan deliberadamente la muerte, sino aliviar o evitar el sufrimiento, respetar la autonomía del paciente y humanizar el proceso de morir y de la muerte. Aceptar el derecho de las personas enfermas a rechazar una determinada intervención sanitaria no es sino mostrar un exquisito respeto a la autonomía personal, a la libertad de cada uno para gestionar su propia biografía asumiendo las consecuencias de las decisiones que toma.

\footnotetext{
${ }^{101}$ Recomendación 1418/1999, de la Asamblea Parlamentaria del Consejo de Europa sobre la protección de los Derechos Humanos y la dignidad de los enfermos terminales y moribundos. La Recomendación 24/2003, del Consejo de Europa, sobre la Organización de los cuidados paliativos, Estas Recomendaciones fueron tomadas en consideración el la Proposición no de Ley sobre cuidados paliativos, aprobada por la comisión de Sanidad del congreso de los Diputados el día 10 de mayo de 2005.

${ }^{102}$ Exposición de Motivos de la Ley 10/2022, de 24 de marzo, de derechos y garantías de la dignidad de la persona en el proceso de morir y de la muerte de Aragón.
} 
El uso inadecuado de medidas de soporte vital, esto es, su aplicación cuando no tienen otro efecto que mantener artificialmente una vida meramente biológica, sin posibilidades reales de recuperación de la integridad funcional de la vida personal, es contraria a la dignidad de la vida humana. Por eso, no iniciar o retirar dichas medidas es algo que sólo aspira a respetar dicha dignidad de forma plena. Facilitar, a aquellas personas en situación terminal que libremente lo deseen, la posibilidad de entrar en la muerte sin sufrimiento, en paz, no puede ser sino otra expresión del respeto a la dignidad del ser humano. Ninguna de estas prácticas puede ser considerada contraria a una ética basada en la idea de dignidad y en el respeto a la Declaración Universal de los Derechos Humanos. Antes al contrario, deben ser consideradas buenas prácticas clínicas y actuaciones profesionales plenamente conformes a la legalidad vigente.

En los últimos años, diversos casos relacionados con el rechazo de tratamiento, la limitación de medidas de soporte vital o la sedación paliativa han sido motivo de debate en la sociedad aragonesa y española. En ellos se han generado dudas acerca de si las actuaciones de los profesionales habían sido éticamente correctas y conformes a Derecho. Esta Ley quiere contribuir decisivamente a proporcionar seguridad jurídica, a la ciudadanía y a los profesionales sanitarios, en las actuaciones contempladas en ella ${ }^{103}$.

\section{Contenido de la Ley}

El articulado de la Ley es prácticamente idéntico a la Ley andaluza aunque existen algunas variaciones que incorporaremos seguidamente.

En el ámbito de las definiciones, art. 5o se señala que se entiende por Adecuación de las medidas terapéuticas, apartado a): "la retirada o no instauración de una medida de soporte vital o de cualquier otra intervención que, dado el mal pronostico del paciente en términos de cantidad o calidad de vida futuras constituye, a juicio de los profesionales sanitarios implicados, algo fútil, que sólo contribuye a prolongar en el tiempo una situación clínica carente de expectativas razonables de mejoría". Así también, se menciona en el apartado f) la Historia de valores, que hace referencia "Al conjunto de documentos que recogen los valores vitales de una persona que dan significado a las decisiones futuras respecto a la atención sanitaria a recibir y respecto al destino del cuerpo o sus órganos y tejidos y a otras disposiciones para después de morir". Finalmente, se menciona en el apartado 1) la Planificación anticipada de las decisiones sanitarias relativas al proceso de morir y de la muerte, indicándose que constituyen "procesos de reflexión y comunicación entre profesionales, pacientes y familiares, que ayudan a mejorar la calidad moral en la toma de decisiones de una persona durante el proceso de morir y de la

\footnotetext{
${ }^{103}$ Exposición de Motivos de la Ley 10/2022, de 24 de marzo, de derechos y garantías de la dignidad de la persona en el proceso de morir y de la muerte de Aragón. 
muerte, atendiendo, entre otros criterios, al documento de voluntades anticipada o a cualquier otro que forme parte de su historia de valores".

Dentro de las garantías que proporcionarán las instituciones y centros sanitarios, se establece en el art. 27 la Creación del Comité de Bioética de Aragón, órgano colegiado, deliberativo, independiente, multidisciplinar, participativo y de carácter consultivo, que desarrollará sus funciones, con plena trasparencia, sobre materias relacionadas con la implicaciones éticas de la medicina y ciencias de la salud, con pleno sometimiento al ordenamiento jurídico. En su actuación, el Comité podrá tomar en consideración otras normas y documentos de referencia internacional (apartado 1). Además, establece que Reglamentariamente, se regularán sus funciones y composición, los derechos y deberes de los miembros del Comité, así como las competencias y procedimientos para el desarrollo de su trabajo (apartado $2^{\circ}$ ).

\section{La Ley Foral de Navarra de Derechos y Garantías de la dignidad de la persona en el proceso de la muerte}

\section{Consideraciones previas}

La iniciativa legislativa de la Comunidad Foral de Navarra en esta materia está contemplada en los artículos 48 y 53 de la Ley Orgánica de Reintegración y Amejoramiento del Régimen Foral ${ }^{104}$.

En este sentido, el derecho a la protección de la salud está contemplado en el artículo 43 de la Constitución de 1978, derecho constitucional desarrollado por la Ley 14/1986, de 25 de abril, General de Sanidad y la Ley 41/2002, Garantías y derechos de los pacientes.

Además de la legislación estatal, las Leyes Forales relativas a la sanidad también contemplan los derechos sanitarios que la presente Ley Foral pretende regular. Así la Ley Foral 17/2010, de 8 de noviembre, de derechos y deberes de las personas en materia de salud ${ }^{105}$, en su artículo 3 , apartados $3^{\circ}$ y $4^{\circ}$ contemplan entre los derechos de la ciudadanía los relativos al respeto a su personalidad, dignidad humana e intimidad, sin discriminación alguna.

\footnotetext{
${ }^{104}$ Ley Orgánica13/1982, de 10 de agosto, de Reintegración y Amejoramiento del Régimen Foral de Navarra. Capítulo II. Delimitación de Facultades y Competencias: Art. 48: Navarra tiene competencias exclusivas en materia de Derecho Civil Foral. Art. 53: 1. En materia de sanidad interior e higiene, corresponden a Navarra las facultades y competencias que actualmente ostenta, y, además, el desarrollo legislativo y la ejecución de la legislación básica del Estado. 2. Dentro de su territorio, Navarra podrá organizar y administrar todos los servicios correspondientes a la materia a la que se refiere el apartado anterior y ejercitará la tutela de las instituciones, entidades y fundaciones relacionadas con las mismas. 3. Sin perjuicio de lo establecido en los apartados anteriores, corresponde al Estado la coordinación y alta inspección conducente al cumplimiento de las facultades y competencias contenidas en este artículo. Ver: http://noticias.juridicas.com/base_datos/Admin/lo13-1982.t2.html\#a48. Consultado 13-082013.

${ }^{105}$ Ley Foral 17/2010, de 8 de noviembre, de derechos y deberes de las personas en materia de salud en la Comunidad Foral de Navarra. Art. 3, apartado 30: Dentro de los Principios Generales de la Ley Foral, Diseñado para todos, El conjunto de servicios e instalaciones sanitarias disponibles se deben concebir o proyectar desde el origen y, siempre que ello sea posible, de tal forma que puedan ser utilizados por todas las personas. Además, en el apartado $4^{\circ}$ : La dignidad de las personas y el respeto a sus valores morales y culturales, así como a sus convicciones religiosas y filosóficas, sin que puedan ser objeto de discriminación por razón de vol.07, nº. 02, Rio de Janeiro, 2014.pp.710-758 743
} 
La presente Ley Foral, Ley 8/2011, de Derechos y Garantías de la dignidad de la persona en el proceso de la muerte, trata de regular y desarrollar los derechos de las personas que se encuentran en el proceso final de la vida, profundizando en el espíritu y la normativa contenida en la Ley Foral 17/2010, de 8 de noviembre, especialmente en lo relativo al artículo 54 de la misma ${ }^{106}$.

Existe un consenso ético y jurídico básico en torno a algunos de los contenidos y derechos del ideal de buena muerte, como son el derecho a recibir cuidados paliativos integrales y de calidad; a no iniciar o retirar medidas de soporte vital cuando no tienen otro efecto que mantener artificialmente una vida meramente biológica, y al respeto de la autonomía de la persona en el proceso de la muerte. Esta Ley Foral pretende así concretar los instrumentos básicos para garantizar esos derechos, usando para ello la información clínica, el consentimiento informado, la toma de decisiones de la persona capaz y el Documento de Voluntades Anticipadas cuando esta no lo es; sobre todo ello incide los artículos de la presente normativa.

Por ello, esta Ley Foral coloca a la persona en el centro de la relación clínica, al entender que es titular de derechos y que debe dirigir su proceso en deliberación con el personal asistencial. Los profesionales no pueden ni deben hacer uso de la información al margen de la persona, ni tampoco tomar decisiones sin contar con ella.

nacimiento, etnia, raza, sexo, religión, opinión o cualquier otra condición o circunstancia personal o social. Ver: http://noticias.juridicas.com/base_datos/CCAA/na-117-2010.tp.html\#a3. Consultado el 13-08-2013.

${ }^{106}$ Voluntades anticipadas: Art. 54 de la Ley Foral 17/2010, de 8 de noviembre: Apartado 1. Todas las personas tienen derecho a decidir sobre las actuaciones sanitarias que les puedan afectar en el futuro en el supuesto de que en el momento en que deban adoptar una decisión no gocen de capacidad para ello.

El documento de voluntades anticipadas es el dirigido al médico responsable en el cual una persona mayor de edad, o un menor al que se le reconoce capacidad conforme a la presente Ley Foral, deja constancia de los deseos previamente expresados sobre las actuaciones médicas para cuando se encuentre en una situación en que las circunstancias que concurran no le permitan expresar personalmente su voluntad, por medio del consentimiento informado, y que deben ser tenidos en cuenta por el médico responsable y por el equipo médico que le asista en tal situación.

En las voluntades anticipadas se podrán incorporar manifestaciones para que, en el supuesto de situaciones críticas, vitales e irreversibles respecto a la vida, se evite el sufrimiento con medidas paliativas aunque se acorte el proceso vital, no se prolongue la vida artificialmente por medio de tecnologías y tratamientos desproporcionados o extraordinarios, ni se atrase abusiva e irracionalmente el proceso de la muerte.

La persona en las manifestaciones de las voluntades anticipadas y a tal efecto, puede designar a un representante para cuando no pueda expresar su voluntad por sí misma. Esta persona será la única interlocutora válida y necesaria con el médico o el equipo sanitario.

En la declaración de voluntad anticipada, la persona interesada podrá hacer constar la decisión respecto de la donación total o parcial de sus órganos para fines terapéuticos, docentes o de investigación. En este supuesto no se requerirá ninguna autorización para la extracción o utilización de los órganos donados.

Apartado 2. El documento de voluntades anticipadas deberá ser respetado por los servicios sanitarios y por cuantas personas tengan alguna relación con el autor del mismo, como si se tratara de un testamento.

Apartado 3. Los médicos o equipos médicos destinatarios de la declaración de voluntades anticipadas no tendrán en cuenta las instrucciones que sean contrarias al ordenamiento jurídico, a la buena práctica clínica, a la mejor evidencia científica disponible o las que no se correspondan con el supuesto de hecho que el sujeto ha previsto en el momento de emitirlas. En estos casos, debe hacerse la anotación razonada pertinente en la historia clínica.

La administración sanitaria adoptará las medidas necesarias para garantizar la voluntad anticipada del paciente recogida en el documento.

Apartado 4. El documento que recoja la declaración de voluntades anticipadas deberá ser entregado por la persona que lo ha otorgado, por sus familiares o por su representante al centro sanitario donde la persona sea atendida. Este documento deberá incorporarse a la historia clínica del paciente. 
Se pretende también en el siguiente articulado incorporar los deberes profesionales que hagan efectivos estos derechos, entre ellos el deber de información y documentación clínica, y el respeto a las decisiones adoptadas libre y voluntariamente.

Todo ello, en definitiva, para consagrar los derechos de autodeterminación decisoria y de autodeterminación informativa de las personas, en el ámbito de la relación clínica.

En las sociedades actuales se asiste en las últimas décadas a espectaculares cambios que se traducen en el aumento de la esperanza de vida y el consiguiente envejecimiento de la población, con un aumento de las enfermedades crónicas e irreversible, que, junto con los importantes avances de la medicina y la ciencia permiten mantener las funciones vitales de las personas hasta límites insospechables, lo que nos lleva a plantearnos nuevas preguntas y retos en función con los procesos de la muerte. Así también, el número creciente de procesos caracterizados por pronóstico vital breve, incurabilidad de la enfermedad causal, intenso sufrimiento personal, físico o moral y familiar, en un contexto de atención sanitaria altamente tecnificada, conforman un escenario de la muerte donde, en una sociedad democrática, el respeto a la libertad, a las creencias religiosas diversas y a la autonomía de la voluntad de la persona ha de mantenerse durante la enfermedad y alcanzar plenamente al proceso de la muerte.

Surge así la necesidad de legislar los derechos y garantías que aseguren la aspiración de morir dignamente con los significados que ello conlleva. Morir con el mínimo sufrimiento físico, psíquico o espiritual. Morir acompañado de los seres queridos. Morir bien informado, si se desea, y no en el engaño falsamente compasivo de una esperanza irreal. Morir pudiendo rechazar los tratamientos que no se desean. Morir según los deseos íntimos previamente expresados en un testamento vital. Morir en la intimidad personal y familiar. Morir, en fin, sin tener que soportar tratamientos que no son útiles y sólo alargan el fin, innecesariamente, proporcionados por profesionales bien intencionados, pero obstinados en terapias no curativas.

Morir bien cuidado, morir a tiempo, morir dormido si se quiere. Morir en paz. Morir "de forma natural", sin prolongación artificial, cuando llegue el momento.

El sufrimiento, forma parte de la naturaleza humana. El dolor es un componente fundamental en el sufrimiento de los pacientes al final de la vida, pero no es el único. Existen variables psicosociales que también condicionan la experiencia de sufrimiento. Se puede reducir la intensidad, la extensión y frecuencia del sufrimiento cuando se realizan intervenciones adecuadas. Pero el enfermo y su familia sufren inevitablemente en la enfermedad. Y la muerte, el final de la vida, es un proceso por naturaleza duro. Por ello en esta Ley Foral se marca como uno de los objetivos el paliar el sufrimiento con todos los recursos posibles. A juicio del legislador no podemos contribuir a la negación total del sufrimiento ya que es preciso prevenir el riesgo de caer en una cierta 
expectativa de absoluto control. Evitando así que los enfermos, sus familiares, los profesionales y el conjunto de la sociedad, consideremos que el sufrimiento en sí, puede ser totalmente evitado.

Por todo ello, el ordenamiento jurídico está llamado a concretar y proteger el ideal de la muerte digna. En este sentido, el rechazo al tratamiento, las limitaciones de medidas de soporte vital y la sedación paliativa reguladas en la presente Ley Foral no deben ser calificadas como acciones eutanásicas, porque no buscan deliberadamente la muerte del enfermo, sino aliviar o evitar el sufrimiento, respetar la autonomía del paciente y humanizar el proceso final de la vida.

Así pues, con el fin de asegurar de manera efectiva la plena dignidad en el proceso del la muerte, la presente Ley Foral no sólo establece y desarrolla los derechos que asisten a las personas en este trance, sino que también determina los deberes del personal sanitario que atiende a las personas en el proceso de muerte y atribuye un conjunto de obligaciones a las instituciones públicas y privadas en orden a garantizar los derechos de las personas, haciéndose constar en la historia clínica la información sobre el proceso terminal y las preferencias del paciente en la toma de decisiones ${ }^{107}$.

\section{Contenido dela Ley}

El articulado de la Ley 8/2011 de Derechos y Garantías de la dignidad de la persona en el proceso de la muerte es prácticamente idéntica a la Ley de Andalucía y Aragón, nosotros señalaremos seguidamente las variaciones que se producen en relación con las Leyes anteriormente desarrolladas.

Se incluye dentro de los fines de la Ley un tercer apartado en el que se regula el ejercicio de los derechos de la persona durante el proceso de la muerte, los deberes del personal sociosanitario que atiende a estos pacientes, así como las garantías que las instituciones sanitarias estarán obligadas a proporcionar, tanto a los pacientes como a los profesionales, con respeto a ese proceso.

Dentro de las definiciones que se contienen en el art. $5^{\circ}$ se hace referencia a dos términos no recogidos en las Leyes citadas anteriormente:

Apartado ñ): Situación terminal: Presencia de una enfermedad avanzada, progresiva, incurable e irreversible, sin posibilidades razonables de respuesta al tratamiento específico, con un pronóstico de vida limitado, y en la que concurren síntomas intensos y cambiantes, así como un gran impacto emocional en pacientes y familiares, lo que requiere una gran intensidad en las intervenciones específicas por parte de los profesionales sanitarios.

\footnotetext{
${ }^{107}$ Exposición de Motivos de la Ley Foral 8/2011, de 24 de marzo, de Derechos y Garantías de la dignidad de la persona en el proceso de la muerte de Navarra: Ver. http://noticias.juridicas.com/base_datos/CCAA/na-18-2011.html. Consultado el 13-082013.
} 
Apartado o) Sedación en la agonía: Sedación paliativa en el grado necesario para aliviar un sufrimiento intenso, físico, psicológico o espiritual, en un paciente en situación de agonía, previo consentimiento informado en los términos establecidos en el art. 8 de la presente Ley Foral ${ }^{108}$, sin perjuicio de lo establecido en la Ley Foral 7/2010, de 8 de noviembre.

\section{REFLEXIONES FINALES}

Ante la ausencia de legislación nacional en relación con la dignidad en el proceso de la muerte, tres Comunidades Autónomas, Andalucía, Aragón y Navarra, han promulgado tres Leyes autonómicas sobre el derecho a la muerte digna. Estamos en presencia de una regulación que abarca cuestiones especialmente sensibles desde el punto de vista constitucional y jurídico, como son: el derecho a la muerte digna, el testamento vital, el derecho al rechazo de tratamientos médicos, sin embargo, no se ha producido una especial problemática entre los legisladores que comparten espacios normativos en esta materia.

Los Estatutos de Autonomía de segunda generación, entre los que queremos destacar el Estatuto de Autonomía de Cataluña y Andalucía, han reconocido algunos derechos relacionados con los derechos de los pacientes, las instrucciones previas, los cuidados paliativos, el derecho al tratamiento del dolor, así como el derecho a la dignidad de la persona en el proceso de la muerte, como ocurre en el caso del Estatuto de Autonomía de Andalucía, Ley 2/2010, adaptando su legislación a la Ley 41/2002, de 14 de noviembre, Básica reguladora de la autonomía del paciente y de derechos y obligaciones en materia de información y documentación clínica.

Los Estatutos de Autonomía y la Jurisprudencia constitucional han venido a confirmar la imposibilidad de que a nivel autonómico se pueda promulgar normas que no cuenten con un respaldo competencia previo en la esfera estatutaria. Por ello, el establecimiento de un régimen específico sobre el derecho a la muerte digna y las voluntades anticipadas no pueden superar las limitaciones básicas ni competenciales.

En algunas Comunidades Autónomas, tras la aprobación de nuevos Estatutos de Autonomía, caso de Andalucía, y en otras sin proceder a la modificación de sus Estatutos de Autonomía, caso de Aragón y Navarra, se han promulgado Leyes autonómicas sobre los derechos y garantías de la dignidad de la persona en el proceso de la muerte que tienen como objeto fundamental: a- regular el ejercicio de los derechos de la persona durante el proceso de su muerte, b- los deberes del personal sanitario que le atiende, c- las garantías que las instituciones sanitarias están obligadas a proporcionar a los pacientes en fase terminal, y d- las infracciones y sanciones.

\footnotetext{
${ }^{108}$ Art. 8 de la Ley Foral 8/2011, Derecho al rechazo y a la retirada de una intervención: 1. Se atenderá a lo establecido en los artículos 26 y 53 de la Ley Foral 17/2010, de 8 de noviembre. 2. Si la persona no pudiera firmar, firmará en su lugar otra persona que actuará como testigo a su ruego, dejando constancia de su identificación y del motivo que impide la firma de quien revoca su consentimiento informado. Todo ello deberá constar por escrito en la historia clínica. 3. En todo caso, las autoridades sanitarias, la administración sanitaria y los profesionales médicos velarán porque todo paciente, independientemente de sus circunstancias reciba los cuidados mínimos acordes con su dignidad según la Lex Artis.
} 
Las tres Leyes autonómicas que se han promulgado en España, Andalucía, Aragón y Navarra han sido el resultado del consenso que existe en sus respectivas sociedades del derecho que tiene toda persona a decidir en relación con los cuidados y tratamiento que quiere recibir en la fase final de su vida.

Estas Leyes han contribuido a proporcionar seguridad jurídica a todos los sujetos implicados en la fase final de la vida de las personas, personal sanitario, pacientes, familiares y centros sanitarios.

Se ha logrado el respeto efectivo de la dignidad de los pacientes en fase terminal, acatando el personal sanitario que le atiende las decisiones que han adoptado en relación con los tratamientos que desean o no recibir. También se han recogido los deberes y obligaciones que tienen, tanto el personal sanitario como los centros sanitarios, tanto públicos como privados a la hora de desarrollar la función que les corresponde en la fase final de la vida de los pacientes. En este caso, se deberá respetar en todo momento la dignidad del enfermo en la fase final de su vida, la autonomía personal y la voluntad del paciente.

La Ley andaluza tiene como fines fundamentales cumplir con el acatamiento de la libertad de elección del paciente a los tratamientos que quiere y no recibir y se debe intentar salvaguardar en los tratamientos y decisiones que se adopten la dignidad del paciente hasta su muerte.

El valor de la dignidad del paciente se contiene no sólo en el conjunto de principios que inspiran las Leyes autonómicas, sino también en el diseño de aquellos instrumentos específicos con los que se realizan sus fines esenciales. Todo ello con el fin de lograr que se garantice una muerte digna. Se trata de asegurar el derecho a una vida digna, en el preciso momento en que se produce el final de aquella.

Las tres Leyes autonómicas contienen un catálogo sistemático de derechos, a partir del cual quedan comprendidas de forma exhaustiva las situaciones que puedan presentarse en el ámbito asistencial y sanitario.

Se establece una clara subordinación a la voluntad del paciente de cualquier intervención médica que se le vaya a practicar. Es por ello que, será necesario contar con el consentimiento previo del paciente antes de procederse a la aplicación de cualquier intervención o técnica médica. El consentimiento deberá obtenerse de forma previa a la intervención y se prestará al menos de forma verbal. También se ha reconocido el derecho a revocar el consentimiento prestado por parte del paciente.

Cuestión trascendente es la que hace referencia en las Leyes de Andalucía y Aragón a que, cuando las voluntades anticipadas realizadas por parte del paciente no se correspondan con las previsiones legislativas, es decir, sean contrarias al ordenamiento jurídico, se tendrá por no puestas. Así también, se establece la vía a través de la que debe resolverse los conflictos que pueden generarse entre la voluntad manifestada de forma anticipada por parte del enfermo terminal y la no previsión de la situación clínica concreta en la que se encuentra el citado paciente. 
Dentro de los derechos de los pacientes se ha reconocido, entre otros, los siguientes derechos: a.- que la vida del paciente no pueda prolongarse contra la voluntad del mismo, b.- los cuidados paliativos y los tratamientos contra el dolor, así como la limitación del esfuerzo terapéutico, entre otros.

Se han establecido determinadas limitaciones en relación a las actividades que desarrollan los profesionales sanitarios en relación a las técnicas de soporte vital que pueden o no adoptar con el fin de evitar la obstinación terapéutica, así como, con la retirada o no instauración de determinadas medidas sanitarias, preservando eso sí, aquellas medidas que sean imprescindibles para mantener de forma adecuada en la fase final de la vida al paciente.

Se ha reconocido el derecho a rechazar un tratamiento o una intervención a todos los pacientes, a pesar de que se conozca que la no intervención o no aplicación de un tratamiento pueda poner en peligro la vida del paciente $\mathrm{o}$ anticipar su muerte.

La Ley andaluza y aragonesa han establecido la posibilidad de limitar las medidas de soporte vital cuya finalidad sea exclusivamente la de prolongar en el tiempo una situación clínica carente de expectativas razonables de mejora. En este sentido, se define la obstinación terapéutica como aplicar o mantener ese tipo de medida, carente de utilidad clínica y encaminada únicamente a prolongar la vida biológica, a pacientes en situación terminal o de agonía y que tienen una enfermedad grave e irreversible.

También se han reconocido como obligación de los profesionales sanitarios y los centros sanitarios, que deriva del ejercicio de una buena práctica clínica que deberá respetar en todo momento los valores, creencias y convicciones personales, morales, religiosas y filosóficas de los pacientes. El respeto a la autonomía y a los valores personales del paciente se constituye en una obligación inexcusable del personal sanitario y el centro sanitario.

Con el objeto de proteger la voluntad del paciente y a su vez el derecho a la objeción de conciencia del personal sanitario, se han establecido las obligaciones que corresponderán a las administraciones sanitarias autonómicas, así como al resto de administraciones e instituciones implicadas, centros sanitarios públicos y privados de tutelar los derechos de los sujetos implicados, para lo que la administraciones competentes deberán arbitrar los medios necesarios para garantizar y compatibilizar el ejercicio de los derechos de pacientes y personal sanitario implicado directamente.

Se han regulado las medidas de apoyo que pueden y tienen que recibir los pacientes y los familiares de los enfermos terminales, a nivel de atención y acompañamiento en el duelo, habitación individual ... siempre que la atención se esté facilitando en los centros sanitarios.

Se ha desarrollado, también, el derecho que tiene el paciente terminal a recibir toda la asistencia sanitaria necesaria en su propio domicilio. 
Se reconoce también a los pacientes en fase terminal todas las atenciones asistenciales existentes en cada momento, entre las que queremos destacar: el tratamiento del dolor, cuidados paliativos de calidad y equitativos y el asesoramiento que sea respetuoso con sus convicciones ideológicas y religiosas.

Se ha recogido el régimen de Infracciones y sanciones que son de aplicación en el caso de que se produzcan incumplimientos por parte del personal sanitario y los centros sanitarios. La preocupación del legislador ha sido la de asegurar que los profesionales y los centros sanitarios no lesionen los derechos de los pacientes, además de dotar de seguridad jurídica a los profesionales y centros sanitarios en la toma de decisiones, regulando los procedimientos que deben seguir en cada caso y estableciendo los órganos asesores para desarrollar de forma efectiva y eficaz la función que se les asigna.

Se han regulado los deberes de los profesionales sanitarios respecto a la toma de decisiones clínicas y en relación a la limitación del esfuerzo terapéutico. Es evidente que el cumplimiento de los deberes que corresponden a los profesionales sanitarios puede provocar la muerte anticipada del paciente, lo que puede generar problemas jurídicos.

Se ha reconocido el derecho a otorgar Instrucciones Previas por parte de los pacientes, para que posteriormente sea respetado el contenido de las mismas cuando el paciente no sea capaz de expresar su voluntad como consecuencia de la fase en la que se encuentra su enfermedad.

A pesar de todo lo que se ha desarrollado hasta este momento en la legislación autonómica, podemos concluir afirmando que "el derecho a la muerte digna se enmarca dentro de un contexto normativo todavía incompleto del que no es posible extraer unos límites precisos sobre su alcance efectivo en aquellas situaciones clínicas donde parece razonable replantearse el grado de esfuerzo terapéutico que hay que poner en práctica para mantener la vida del paciente y la voluntad que ha sido manifestada de forma anticipada por el mismo".

\title{
RIGHTS AND GUARANTEES OF THE DIGNITY OF THE PERSON IN THE PROCESS OF THE DEAD: ESPECIAL REFERENCE TO THE AUTONOMOUS LAWS OF ANDALUSIA, ARAGON AND NAVARRE.
}

\begin{abstract}
:
Three Autonomous Spanish Communities have promulgated recently Laws that it tries to protect the rights of the patients in the final phase of his life. It has been a question of protecting the dignity of the patients in the terminal phase and to respecting his will demonstrated expressly.
\end{abstract}

Keywords: Patient's Autonomy, Right to refuse medical treatment, Process of dying, Dignity of the patient, Right to die. 


\section{BIBLIOGRAFÍA}

ARRUEGO RODRÍGUEZ, G. "El derecho del paciente a rechazar el tratamiento en la nueva normativa sobre el "proceso de la muerte", en Autonomía personal, cuidados paliativos y Derecho a la vida, PRESNO LINERA, M. A. (Coordinador), Procura, n 1, 2011. ARRUEGO RODRÍGUEZ, G. "El rechazo y la interrupción del tratamiento de soporte vital en el Derecho español", en INDRET, n² 2, 2009.

BASTIDA FREIJEDO, F. J. (2011) "El derecho fundamental a la vida y la autonomía del paciente", en PRESNO LINERA, M. A. (Coordinador), Autonomía Personal, Cuidados Paliativos y Derecho a la Vida, Procura, no 1 2011.

CHUEVA RODRÍGUEZ, R. "El marco constitucional del final de la propia vida", en Revista de Derecho Constitucional, no 85, 2009.

LABACA ZABALA Ma LOURDES, (2006) "El Consentimiento informado en el ámbito sanitario, a propósito de la Ley 41/2002, Básica Reguladora de la Autonomía del paciente y de los Derechos y Obligaciones en materia de información y documentación clínica", en Saberes: Revista de Estudios Jurídicos, Económicos y Sociales, volumen no 4, 2006., pp. 3 yss.

LABACA ZABALA Ma LOURDES, (2007) "La Ley de voluntades anticipadas en el ámbito de la sanidad del País Vasco", en Revista Âmbito Juridico, Universidad Río Grande-Brasil. Ver: http://www.ambitojuridico.com.br/site/index.php?n_link=revista_artigos_leitura\&artigo_id=1229. (Consultado el día 23-042013).

LEAL ADORNA, M. M. (2012) "Ley Andaluza de Derechos y Garantías de la Dignidad de la Persona en el Proceso de la Muerte: Sus problemas presentes y futuros", en Cuestiones de Derecho Eclesiástico del Estado: In Memoriam Ález Seglers, Coordinadores, ROSSELL, J.y GARCÍA GARCÍA, R.

MARTÍN GÓMEZ, J. A. "Eutanasia: aproximación al tratamiento jurídico de la disponibilidad vital", en Revista Jurídica de Cataluña, año XCLC, no 3, 1995. Del mismo autor: "Reflexiones sobre la eutanasia: Una cuestión pendiente del Derecho Constitucional a la vida”, en Revista de Derecho Constitucional, n 54, 1998.

MORENO ANTÓN, M. (2004) "Elección de la propia muerte y Derecho: Hacía el reconocimiento jurídico del derecho a morir”, en Derecho Sanitario, volumen 12, número 1, enero-junio 2004.

NADAL, C. e PINCEMIN, I. "Cuidados paliativos: derecho al final de la vida", en Revista Debate Público. Reflexión de Trabajo Social, año 2, no 4.

RODRIGUEZ, A. "Muerte digna y Derechos en los Estatutos de Autonomía”, en Autonomía personal, Cuidados paliativos y Derecho a la vida, PRESNO LINERA M. A. (Coordinador), Procura, no 1, 2011.

ROMEO CASABONA, C. M. El derecho y la bioética ante los límites de la vida humana, 1994.

RUIZ-RICO RUIZ, G. "El derecho a una muerte digna desde la perspectiva del Estado Autonómico español. Una especial referencia al caso de la legislación andaluza”, en Revista de la Facultad de Ciencias Jurídicas, n $14-15$ $2009 / 10$. 
RUÍZ MIGUEL, A. "Autonomía individual y derecho a la propia muerte", en Revista Española de Derecho Constitucional, n 89, 2010.

SARMIENTO-MEDINA, M. I. VARGAS-CRUZ, S. L, VELÁSQUEZ-JIMÉNEZ, C. M. SIERRA DE JARAMILLO, M. (2012) "Problemas y decisiones al final de la vida en pacientes con enfermedad en etapa terminal”, en Revista Salud pública, no 14-(1).

TOMÁS-VALIENTE LANUZA C. La disponibilidad de la propia vida en el Derecho Penal, 1999. De la misma autora: "La disponibilidad de la propia vida: aspectos constitucionales", en El derecho a la vida, Tribunal Constitucional-CEPC, 2003.

Trabalho enviado em 30 de maio de 2014. Aceito em 16 de agosto de 2014. 